\title{
GPR120 Signaling Controls Amyloid- $\beta$ Degrading Activity of Matrix Metalloproteinases
}

\author{
Kazunori Kikuchi, ${ }^{1}$ Takuya Tatebe, ${ }^{1,2}$ Yuki Sudo, ${ }^{1}$ Miyabishara Yokoyama, ${ }^{1}$ Kiwami Kidana, ${ }^{1,3}$ Yung Wen Chiu, ${ }^{1}$ \\ Sho Takatori, ${ }^{1}$ Makoto Arita, ${ }^{4,5}$ Yukiko Hori, ${ }^{1}$ and ${ }^{1}$ Taisuke Tomita ${ }^{1}$ \\ ${ }^{1}$ Laboratory of Neuropathology and Neuroscience, Graduate School of Pharmaceutical Sciences, The University of Tokyo, Tokyo, 113-0033, Japan, ${ }^{2}$ Faculty of \\ Pharmaceutical Sciences, Teikyo Heisei University, Tokyo, 164-8530, Japan, ${ }^{3}$ Department of Home Care Medicine, Graduate School of Medicine, The \\ University of Tokyo, Tokyo, 113-0033, Japan, ${ }^{4}$ Division of Physiological Chemistry and Metabolism, Graduate School of Pharmaceutical Sciences, Keio \\ University, Tokyo, 105-8512, Japan, and ${ }^{5}$ Laboratory for Metabolomics, RIKEN Center for Integrative Medical Sciences, Kanagawa, 230-0045, Japan
}

Alzheimer's disease $(\mathrm{AD})$ is characterized by the extensive deposition of amyloid- $\boldsymbol{\beta}$ peptide $(\mathrm{A} \boldsymbol{\beta})$ in the brain. Brain $\mathrm{A} \boldsymbol{\beta}$ level is regulated by a balance between $\mathrm{A} \beta$ production and clearance. The clearance rate of $\mathrm{A} \boldsymbol{\beta}$ is decreased in the brains of sporadic $\mathrm{AD}$ patients, indicating that the dysregulation of $\mathrm{A} \beta$ clearance mechanisms affects the pathologic process of $\mathrm{AD}$. Astrocytes are among the most abundant cells in the brain and are implicated in the clearance of brain $\mathrm{A} \beta$ via their regulation of the blood-brain barrier, glymphatic system, and proteolytic degradation. The cellular morphology and activity of astrocytes are modulated by several molecules, including $\omega 3$ polyunsaturated fatty acids, such as docosahexaenoic acid, which is one of the most abundant lipids in the brain, via the G protein-coupled receptor GPR120/FFAR4. In this study, we analyzed the role of GPR120 signaling in the A $\beta$-degrading activity of astrocytes. Treatment with the selective antagonist upregulated the matrix metalloproteinase (MMP) inhibitor-sensitive A $\beta$-degrading activity in primary astrocytes. Moreover, the inhibition of GPR120 signaling increased the levels of Mmp2 and Mmp14 mRNAs, and decreased the expression levels of tissue inhibitor of metalloproteinases 3 (Timp3) and Timp4, suggesting that GPR120 negatively regulates the astrocyte-derived MMP network. Finally, the intracerebral injection of GPR120-specific antagonist substantially decreased the levels of TBS-soluble $\mathrm{A} \boldsymbol{\beta}$ in male AD model mice, and this effect was canceled by the coinjection of an MMP inhibitor. These data indicate that astrocytic GPR120 signaling negatively regulates the A $\beta$-degrading activity of MMPs.

Key words: Alzheimer; amyloid-beta; astrocyte; degradation; matrix metalloproteinase; protease

\section{Significance Statement}

The level of amyloid $\beta(\mathrm{A} \beta)$ in the brain is a crucial determinant of the development of Alzheimer's disease. Here we found that astrocytes, which are the most abundant cell type in the CNS, harbor degrading activity against $\mathrm{A} \beta$, which is regulated by GPR120 signaling. GPR120 is involved in the inflammatory response and obesity in peripheral organs. However, the pathophysiological role of GPR120 in Alzheimer's disease remains unknown. We found that selective inhibition of GPR120 signaling in astrocytes increased the $\mathrm{A} \beta$-degrading activity of matrix metalloproteases. Our results suggest that GPR120 in astrocytes is a novel therapeutic target for the development of anti- $\mathrm{A} \beta$ therapeutics.

Received 0ct. 7, 2020; revised May 16, 2021; accepted May 26, 2021.

Author contributions: K. Kikuchi, T. Tatebe, K. Kidana, and T. Tomita designed research; K. Kikuchi, Y.S., M.Y., and Y.W.C. performed research; K. Kikuchi, M.Y., Y.W.C., S.T., Y.H., and T. Tomita analyzed data; K. Kikuchi wrote the first draft of the paper; K. Kikuchi, T. Tatebe, K. Kidana, M.A., Y.H., and T. Tomita edited the paper; K. Kikuchi and T. Tomita wrote the paper; M.A. contributed unpublished reagents/analytic tools.

This work was supported by Japan Society for the Promotion of Science Grants-in-aid for Scientific Research (A) 15 H02492 and 19 H01015 to T. Tomita; and Japan Agency for Medical Research and Development Strategic Research Program for Brain Sciences 19dm0107056h0004 to T. Tomita. The results of the MayoRNAseq Study and Mount Sinai Brain Bank data were published in whole or in part based on data obtained from the AMP-AD Knowledge Portal (https://adknowledgeportal.synapse.org/). The MayoRNAseq Study data were provided by the following sources: Mayo Clinic Alzheimer's Disease Genetic Studies, led by Dr. Nilufer Taner and Dr. Steven G. Younkin (Mayo Clinic, Jacksonville, FL) using samples from the Mayo Clinic Study of Aging, the Mayo Clinic Alzheimer's Disease Research Center, and the Mayo Clinic Brain Bank. Data collection was supported through funding by National Institute on Aging Grants P50 AG016574, R01 AG032990, U01 AG046139, R01 AG018023, U01 AG006576, U01 AG006786, R01 AG025711, R01 AG017216, and R01 AG003949; National Institute of Neurological Disorders and Stroke Grant R01 NS080820; CurePSP Foundation; and Mayo Foundation. Study data include samples collected through the Sun Health Research Institute Brain and Body Donation Program (Sun City, AZ). The
Brain and Body Donation Program was supported by National Institute of Neurological Disorders and Stroke (U24 NS072026 National Brain and Tissue Resource for Parkinson's Disease and Related Disorders), National Institute on Aging (P30 AG19610 Arizona Alzheimer's Disease Core Center), Arizona Department of Health Services (Contract 211002, Arizona Alzheimer's Research Center), Arizona Biomedical Research Commission (Contracts 4001, 0011, 05-901, and 1001 to the Arizona Parkinson's Disease Consortium), and Michael J. Fox Foundation for Parkinson's Research. The Mount Sinai Brain Bank data were generated from postmortem brain tissue collected through the Mount Sinai Veterans Administration Medical Center Brain Bank and were provided by Dr. Eric Schadt (Mount Sinai School of Medicine). We thank Drs. Takeshi Iwatsubo (The University of Tokyo) for APP/PS1 mice; Haruhiko Bito (The University of Tokyo) for lentivirus vectors; Edward Koo (University of California, San Diego) for 7PA2 cells; Keisuke Horiuchi and Yasunori Okada (Keio University) for mouse sample; Hideki Kitaura and Itaru Mizoguchi (Tohoku University) for mouse sample; Atsuhiko Ichimura (Kyoto University) for mouse sample; and current and previous laboratory members for helpful discussions.

The authors declare no competing financial interests.

Correspondence should be addressed to Taisuke Tomita at taisuke@mol.f.u-tokyo.ac.jp.

https://doi.org/10.1523/JNEUROSCI.2595-20.2021

Copyright $\odot 2021$ the authors 
Table 1. Primer sequences for qRT-PCR

\begin{tabular}{|c|c|c|c|}
\hline Gene ID & Full name & Forward primer sequence & Reverse primer sequence \\
\hline Ace & Angiotensin-converting enzyme & GAGCTGGAGAGACAAGGTGG & GTGTAGCCATTGAGCTTGGC \\
\hline Apeh & Acylpeptide hydrolase & GCTCTTCCTGTATGACTGGTACAC & ACCGAGTCGAAGACCACTCT \\
\hline Bsg & Basigin & CGAAGTACATAGTGGACGCAGA & CATCGGACTTGCAGACCAGT \\
\hline Ctsb & Cathepsin B & CCGAACCTGCATTCACACCA & AAGCAGCCTACATGAGAATTGTAGA \\
\hline Ctsd & Cathepsin D & CCTTCGCGATTATCAGAATCCCTC & ACGACTGTGAAACACTGCGG \\
\hline Gpr120 & Gpr120 & TTGTGACTTTGAACTTCCTGGTG & GTATGCCAAGCTCAGCGTAAG \\
\hline Gapdh & Glyceraldehyde 3-phosphate dehydrogenase & AGGTCGGTGTGAACGGATTTG & TGTAGACCATGTAGTTGAGGTCA \\
\hline Ide & Insulin-degrading enzyme & CCACGAGGCTATACGTCCAA & AAACTATTGCCACCCGCACA \\
\hline Klk7 & Kallikrein-related peptidase 7 & ACTCCACAAAGACCCACGTC & CGAGGGAAAGGTCACGTCTG \\
\hline$M b p$ & Myelin basic protein & GGCATCCTTGACTCCATCGG & TCCTTGTACATGTGGCACAGC \\
\hline Mme & Membrane metallo-endopeptidase & AACTTTGCCCAGGTGTGGTG & AAAGGCATCTGCAAACTCGG \\
\hline Mmel1 & Membrane metalloendopeptidase-like 1 & CCACCGAATGGACCTGATGG & GCATGGTCCGTGCTGAGTAG \\
\hline Mmp14 & MMP 14 & CCAAGGCAGCAACTTCAGC & GTGAGCGTTGTGTGTGGGTA \\
\hline Mmp2 & MMP 2 & CAAGTTCCCCGGCGATGTC & TTCTGGTCAAGGTCACCTGTC \\
\hline Mmp9 & MMP 9 & GCGTCATTCGCGTGGATAAG & CCTGGTTCACCTCATGGTCC \\
\hline Plat & Tissue-type plasminogen activator & AGCGAGGACTGCTATGTTGG & TCACCATCTGGATTCCGACAA \\
\hline $\mathrm{Plg}$ & Plasminogen & CAGATTCCTCAGTTCCACCAGA & AGTTCATCTCCAAGCCAGCA \\
\hline Timp1 & TIMPs 1 & AGACACACCAGAGCAGATACC & TGGTATAAGGTGGTCTCGTTGATT \\
\hline Timp2 & TIMPs 2 & AGTGCAAGATCACTCGCTGT & CGCGCAAGAACCATCACTTC \\
\hline Timp3 & TIMPs 3 & TGCCTTCTGCAACTCCGAC & TGAAGCCTCGGTACATCTTCATC \\
\hline Timp4 & TIMPs 4 & TTGACTGGCCAGATTCTCAGT & GCACTGCATAGCAAGTGGTG \\
\hline Ace & Angiotensin-converting enzyme & GAGCTGGAGAGACAAGGTGG & GTGTAGCCATTGAGCTTGGC \\
\hline Apeh & Acylpeptide hydrolase & GCTCTTCCTGTATGACTGGTACAC & ACCGAGTCGAAGACCACTCT \\
\hline Bsg & Basigin & CGAAGTACATAGTGGACGCAGA & CATCGGACTTGCAGACCAGT \\
\hline Ctsb & Cathepsin B & CCGAACCTGCATTCACACCA & AAGCAGCCTACATGAGAATTGTAGA \\
\hline Ctsd & Cathepsin D & CCTTCGCGATTATCAGAATCCCTC & ACGACTGTGAAACACTGCGG \\
\hline Gpr120 & Gpr120 & TTGTGACTTTGAACTTCCTGGTG & GTATGCCAAGCTCAGCGTAAG \\
\hline Gapdh & Glyceraldehyde 3-phosphate dehydrogenase & AGGTCGGTGTGAACGGATTTG & TGTAGACCATGTAGTTGAGGTCA \\
\hline Ide & Insulin-degrading enzyme & CCACGAGGCTATACGTCCAA & AAACTATTGCCACCCGCACA \\
\hline Klk7 & Kallikrein-related peptidase 7 & ACTCCACAAAGACCCACGTC & CGAGGGAAAGGTCACGTCTG \\
\hline$M b p$ & Myelin basic protein & GGCATCCTTGACTCCATCGG & TCCTTGTACATGTGGCACAGC \\
\hline Mme & Membrane metallo-endopeptidase & AACTTTGCCCAGGTGTGGTG & AAAGGCATCTGCAAACTCGG \\
\hline Mmel1 & Membrane metalloendopeptidase-like 1 & CCACCGAATGGACCTGATGG & GCATGGTCCGTGCTGAGTAG \\
\hline Mmp14 & MMP 14 & CCAAGGCAGCAACTTCAGC & GTGAGCGTTGTGTGTGGGTA \\
\hline Mmp2 & MMP 2 & CAAGTTCCCCGGCGATGTC & TTCTGGTCAAGGTCACCTGTC \\
\hline Mmp9 & MMP 9 & GCGTCATTCGCGTGGATAAG & CCTGGTTCACCTCATGGTCC \\
\hline Plat & Tissue-type plasminogen activator & AGCGAGGACTGCTATGTTGG & TCACCATCTGGATTCCGACAA \\
\hline $\mathrm{Plg}$ & Plasminogen & CAGATTCCTCAGTTCCACCAGA & AGTTCATCTCCAAGCCAGCA \\
\hline Timp1 & TIMPs 1 & AGACACACCAGAGCAGATACC & TGGTATAAGGTGGTCTCGTTGATT \\
\hline Timp2 & TIMPs 2 & AGTGCAAGATCACTCGCTGT & CGCGCAAGAACCATCACTTC \\
\hline Timp3 & TIMPs 3 & TGCCTTCTGCAACTCCGAC & TGAAGCCTCGGTACATCTTCATC \\
\hline Timp4 & TIMPs 4 & TTGACTGGCCAGATTCTCAGT & GCACTGCATAGCAAGTGGTG \\
\hline
\end{tabular}

\section{Introduction}

Alzheimer's disease $(\mathrm{AD})$ is the most common neurodegenerative disorder among the dementias. It is characterized by the extensive deposition of amyloid- $\beta$ peptide $(\mathrm{A} \beta)$ as senile plaques in the brain. $A \beta$ is mainly secreted from neuronal cells by the proteolytic processing of amyloid precursor protein (APP). This processing is performed sequentially by $\beta$-site APP cleaving enzyme 1 (BACE1) and $\gamma$-secretase. Genetic analyses demonstrated that many autosomal-dominant AD mutations augment A $\beta$ production or aggregation (Kikuchi et al., 2017; Tomita, 2017), and the point mutation encoding for A673T in $\mathrm{A} \beta$ sequence protects against $\mathrm{AD}$ and cognitive decline in older people without AD (Jonsson et al., 2012). In sporadic patients, whereas $\mathrm{A} \beta$ production was found to be unaltered, the clearance rate of brain $\mathrm{A} \beta$ was significantly decreased (Mawuenyega et al., 2010). Thus, the dysregulation of $\mathrm{A} \beta$ clearance affects brain $\mathrm{A} \beta$ level, the deposition of senile plaques, and the pathologic process of $\mathrm{AD}$. Recently, the pathophysiological contribution of astrocytes in $\mathrm{A} \beta$ clearance has been highlighted. Astrocytes modulate the blood-brain barrier, phagocytic activity, the glymphatic system, and activities of $\mathrm{A} \beta$-degrading enzymes (Saido and Leissring, 2012; Ries and Sastre, 2016). However, the precise regulatory mechanism of $\mathrm{A} \beta$-degrading enzymes remains unclear.

The brain is a lipid-enriched organ in the body. Lipids account for about half of the dry weight of the brain (O'Brien and Sampson, 1965; Liu et al., 2015), and include polyunsaturated fatty acids (PUFAs). PUFAs are mostly esterified and exist in the cellular membrane, and are partially released from the membrane by the activity of phospholipases. These unesterified PUFAs and their metabolites function as lipid mediators, and transduce various cellular signaling pathways via their cognate receptors (Ishihara et al., 2019). Epidemiological studies have shown that a high consumption of $\omega 3$ PUFAs, such as docosahexaenoic acids (DHA), is associated with a reduced risk of $\mathrm{AD}$ (Morris et al., 2003). Many studies also suggested the multifunctional beneficial effects of $\omega 3$ PUFAs on AD (Bazinet and Layé, 2014). DHA in the cellular membrane prevents $\mathrm{A} \beta$-induced neuronal apoptosis by activation of the extracellular signal- 
regulated kinase (ERK) pathway (Florent et al., 2006; Kim et al., 2010). Additionally, neuroprotectin D1, a lipid mediator derived from DHA (Schwab et al., 2007), suppressed A $\beta$ production via peroxisome proliferator-activated receptor $\gamma$ (Zhao et al., 2011). Other reports suggested that DHA induces the differentiation, inflammatory response, and morphologic changes of astrocytes (Heras-Sandoval et al., 2016; Das and Das, 2019; Yu et al., 2020). However, the effects of $\omega 3$ PUFAs on the $\mathrm{A} \beta$-degrading activity of astrocytes are not well characterized.

$\omega 3$ PUFAs activate the GPCR GPR120/FFAR4 (Hirasawa et al., 2005; Oh and Olefsky, 2016). GPR120 is widely expressed in various tissues, including the gastrointestinal tract, adipose tissue, and brain. GPR120 signaling facilitates the activities of glucagon-like peptide-1 in the gut (Hirasawa et al., 2005), promotes adipogenesis in adipose tissue (Gotoh et al., 2007; Hilgendorf et al., 2019), and suppresses the activation of the macrophages induced inflammatory response (Oh et al., 2010). Thus, the therapeutic potential of GPR120 has focused on Type 2 diabetes (Oh and Olefsky, 2016; Milligan et al., 2017). Moreover, recent studies showed that GPR120 is expressed in astrocytes, microglia, and neuronal cells (Ren et al., 2019), and DHA treatment regulates the morphology of astrocytes via GPR120 signaling (Das and Das, 2019). However, the association between GPR 120 and A $\beta$ clearance by astrocytes remains unclear. Therefore, in this study, we analyzed the mechanism by which GPR120 signaling regulates the $\mathrm{A} \beta$ degrading activity of astrocytes.

\section{Materials and Methods}

Cell culture and compounds. All cells used in this report were cultured in DMEM with high glucose (Wako) containing 10\% heat-inactivated FBS (Hyclone), $50 \mathrm{unit} / \mathrm{ml}$ penicillin (Wako), and $50 \mathrm{units} / \mathrm{ml}$ streptomycin (Wako) at $37^{\circ} \mathrm{C}$ in humidified $5 \% \mathrm{CO}_{2}$ air (Tomita et al., 1997; Kidana et al., 2018). Primary glial cells, mainly comprised of astrocytes, were obtained as previously described with some modifications (Fukumoto et al., 1999; Kidana et al., 2018). Briefly, we isolated cerebrum from postnatal day 2 mice of either sex in ice-cold HBSS(-) (Wako). The cerebrum was suspended in HBSS containing 0.25\% trypsin, $0.1 \mu \mathrm{l} / \mathrm{ml}$ DNase (Nippon Gene), $0.8 \mathrm{~mm} \mathrm{MgSO}_{4}$ (Kanto), and 1.85 $\mathrm{mm} \mathrm{CaCl} 2$ (Kanto) at $37^{\circ} \mathrm{C}$ for $15 \mathrm{~min}$. The obtained cell suspension was passed through a $100 \mu \mathrm{m}$ cell strainer (Falcon) and centrifuged with culture medium. The cell pellet was resuspended in culture medium and seeded on cell culture plate. The culture medium was renewed at 4 DIV and thereafter every 2-3 d. 7PA2 cell (Podlisny et al., 1995), a cell line obtained by transfecting human APP751 with V717F mutation to Chinese hamster ovary cells, was kindly provided by Dr. Edward Koo (University of California, San Diego). The conditioned medium (CM) of 7PA2 cells (7PA2 CM) cultured at confluency for $2 \mathrm{~d}$ was collected and centrifuged at $6000 \times g$ for $10 \mathrm{~min}$ at $4^{\circ} \mathrm{C}$ to remove cell debris. Then, A $\beta 40$ level in 7PA2 CM was determined by ELISA (Human/Rat $\beta$ Amyloid(40) ELISA Kit Wako II, Wako, catalog \#294-64701). Cell viability was checked by using alamarBlue Cell Viability Reagent (Thermo Fisher Scientific, catalog \#DAL1025). Docosahexaenoic acid (Cayman Chemical, catalog \#90310), compound A (Cayman Chemical, catalog \#16624), AH7614 (Focus Biomolecules, catalog \#10-1521), and GM6001 (Enzo Life Science, catalog \#BML-EI300-0005) were purchased from the indicated suppliers.

Immunologic methods. Samples were dissolved in Laemmi sample buffer (final concentration: $2 \%$ SDS, $80 \mathrm{~mm}$ Tris- $\mathrm{HCl} \mathrm{pH} \mathrm{6.8,} 10 \%$ glycerol, $0.0025 \%$ Brilliant green [Wako], 0.00625\% Coomassie Brilliant Blue G250 [Nacalai Tesque]) and boiled for $5 \mathrm{~min}$ at $100^{\circ} \mathrm{C}$. For detection of membrane proteins in $2 \%$ Triton X-100-soluble fraction extracted from mouse hippocampus, samples were incubated $5 \mathrm{~min}$ at $65^{\circ} \mathrm{C}$ instead of boiling. Western blotting was performed as described previously (Tomita et al., 1997; Kidana et al.,
Table 2. The sequences of primers for lentiviral shRNA constructs

\begin{tabular}{|c|c|}
\hline shRNAs & Primer sequence $^{a}$ \\
\hline \multirow[t]{2}{*}{ shLuci } & CCGGCTTACGCTGAGTACTTCGACTCGAGTCGAAGTACTCAGCGTAAGTTTTTG \\
\hline & AATTCAAAAACTTACGCTGAGTACTTCGACTCGAGTCGAAGTACTCAGCGTAAG \\
\hline \multirow[t]{2}{*}{ shGpr120 \#1 } & CCGGCGAAATGACTTGTCTGTTATTCTCGAGAATAACAGACAAGTCATTTCGTTTTTG \\
\hline & AATTCAAAAACGAAATGACTTGTCTGTTATTCTCGAGAATAACAGACAAGTCATTTCG \\
\hline \multirow[t]{2}{*}{ shGpr120 \#2 } & $\begin{array}{l}\text { CCGGCCCAACCGCATAGGAGAAATCTCATCTCGAGATGAGATTTCTCCTATGCGGTT } \\
\text { GGGTTTTTG }\end{array}$ \\
\hline & $\begin{array}{l}\text { AATTCAAAAACCCAACCGCATAGGAGAAATCTCATCTCGAGATGAGATTTCTCCTA } \\
\text { TGCGGTTGGG }\end{array}$ \\
\hline \multirow[t]{2}{*}{ shMmp2 \#1 } & CCGGGCTGAAAGATACCCTCAAGAACTCGAGTTCTTGAGGGTATCTTTCAGCTTTTTG \\
\hline & AATTCAAAAAGCTGAAAGATACCCTCAAGAACTCGAGTTCTTGAGGGTATCTTTCAGC \\
\hline \multirow[t]{2}{*}{ shMmp2 \#2 } & CCGGGCTGTGTTCTTCGCAGGGAATCTCGAGATTCCCTGCGAAGAACACAGCTTTTTG \\
\hline & AATTCAAAAAGCTGTGTTCTTCGCAGGGAATCTCGAGATTCCCTGCGAAGAACACAGC \\
\hline \multirow[t]{2}{*}{ shMmp9 \#1 } & CCGGGAGGCATACTTGTACCGCTATCTCGAGATAGCGGTACAAGTATGCCTCTTTTTG \\
\hline & AATTCAAAAAGAGGCATACTTGTACCGCTATCTCGAGATAGCGGTACAAGTATGCCTC \\
\hline \multirow[t]{2}{*}{ shMmp9 \#2 } & CCGGCCACTTACTATGGAAACTCAACTCGAGTTGAGTTTCCATAGTAAGTGGTTTTTG \\
\hline & AATTCAAAAACCACTTACTATGGAAACTCAACTCGAGTTGAGTTTCCATAGTAAGTGG \\
\hline \multirow[t]{2}{*}{ shMmp9 \#1 } & CCGGGCAGTGATGAAGTCTTCACATCTCGAGATGTGAAGACTTCATCACTGCTTTTTG \\
\hline & AATTCAAAAAGCAGTGATGAAGTCTTCACATCTCGAGATGTGAAGACTTCATCACTGC \\
\hline \multirow[t]{2}{*}{ shMmp9 \#2 } & CCGGCCATCAATACTGCCTACGAAACTCGAGTTTCGTAGGCAGTATTGATGGTTTTTG \\
\hline & AATTCAAAAACCATCAATACTGCCTACGAAACTCGAGTTTCGTAGGCAGTATTGATGG \\
\hline
\end{tabular}

${ }^{a}$ Upper, forward primer; lower, reverse primer.

2018). A $\beta 40$ and $\mathrm{A} \beta 42$ derived from 7 PA2 CM were detected by SDS-PAGE using acrylamide gel containing $8 \mathrm{~m}$ urea (urea/SDSPAGE), as described previously (Qi-Takahara et al., 2005; Ohki et al., 2011). For assessment of immunoreactivity, chemical fluorescence of ImmunoStar detection kit (Wako, catalog \#291-55203) or Supersignal West Femto (Pierce, catalog \#34096) was detected by Image Quant LAS 4000 (GE Healthcare). Signal intensity was quantified by ImageQuant TL software (GE Healthcare). For A $\beta$-degrading assay, DIV12-DIV14 primary astrocytes were treated $20 \mathrm{nM}$ synthetic human A $\beta 40$ (Peptide Institute, catalog \#4307-v) or 7PA2 $\mathrm{CM}$ (final $\mathrm{A} \beta 40$ concentration: $2 \mathrm{nM}$ ) with compounds (Kidana et al., 2018). After indicated times, levels of remaining $A \beta$ were analyzed by Western blotting. The antibodies for the Western blotting were the following: anti-human A $\beta$ (82E1, IBL, catalog \#10323, 1:2500 dilution), anti- $\alpha$-tubulin (DM1A, Sigma Millipore, catalog \#T9026, 1:5000 dilution), anti-human sAPP $\beta$-sw (6A1, IBL, catalog \#10321, 1:200), anti-BACE1 (BACE1(c), Wako, catalog \#18711, 1:1000 dilution), and anti- $\mathrm{Na}^{+} / \mathrm{K}^{+}$-ATPase (a6F, DSHB, RRID: $\mathrm{AB}_{-}$ 528092, 1:1000 dilution).

qRT-PCR. Total RNA was extracted from cells using Isogen (Nippon Gene, catalog \#311-02501). Then, cDNA synthesis from total RNA was performed using ReverTra Ace qPCR RT Master Mix with gDNA Remover (Toyobo, catalog \#FSQ-301) according to the supplier's instruction. cDNA mixed with gene-specific primers and Thunderbird SYBR qPCR Mix (Toyobo, catalog \#QPS-201), and qRT-PCR was run on LightCycler 480 Instrument (Roche). The PCR condition was as follows: 1 cycle of denaturation $\left(95^{\circ} \mathrm{C}, 1 \mathrm{~min}\right)$; 50 cycles of denaturation $\left(95^{\circ} \mathrm{C}, 10 \mathrm{~s}\right)$, annealing $\left(60^{\circ} \mathrm{C}, 30 \mathrm{~s}\right)$, and extension $\left(72^{\circ} \mathrm{C}, 1 \mathrm{~min}\right)$. Specificity was confirmed by melting curve analysis and agarose gel electrophoresis. The sequences of primers used qRT-PCR are listed in Table 1.

Preparation of lentiviral short hairpin RNA. pLKO.1-puro vector (a gift from Bob Weinberg, Addgene plasmid \#8453; http://n2t.net/ addgene:8453; RRID:Addgene_8453) is lentiviral vector for small interfering RNA expression encoding puromycin resistance gene under the human phosphoglycerate kinase promoter (Stewart et al., 2003). We removed the puromycin resistance gene from this vector and inserted EGFP gene to construct the pLKO.1-EGFP vector (Chiu et al., 2020). Short hairpin RNA (shRNA) sequences were cloned into pLKO.1-EGFP according to the protocol by Addgene. The sequences of primers used for plasmid construction are listed in Table 2. Two different shRNA sequences (\#1 and \#2) were designed for each gene, based on GPP Web Portal site (https://portals.broadinstitute. org/gpp/public/) and Invitrogen BLOCK-iT RNAi Designer 
A

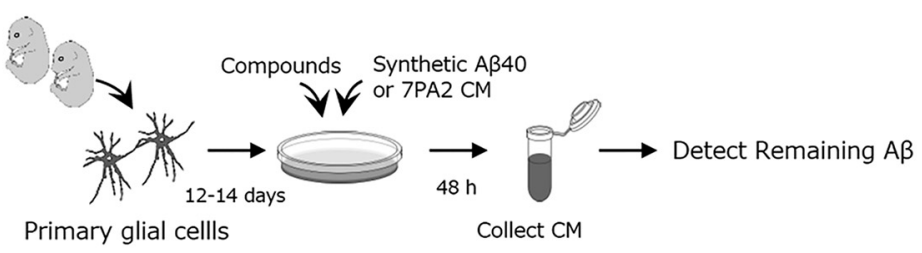

B

C

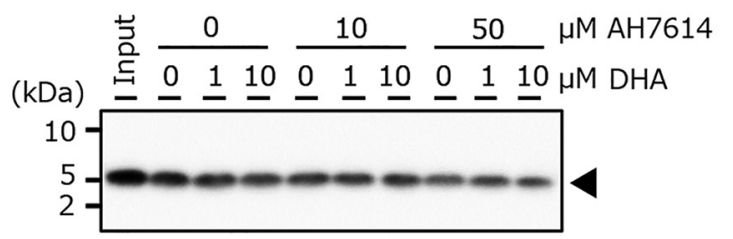

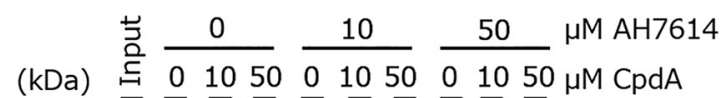
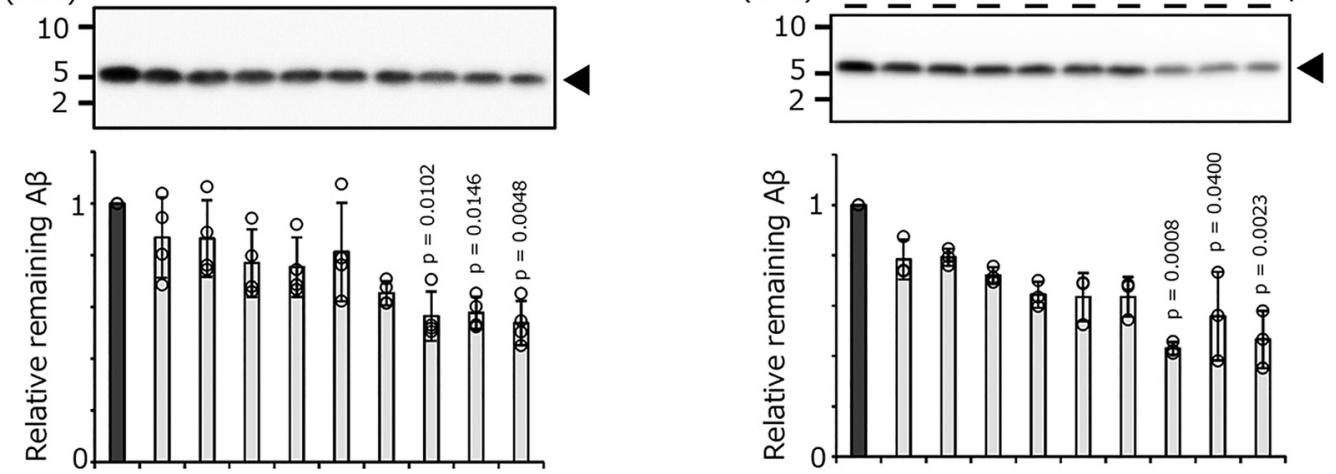

D
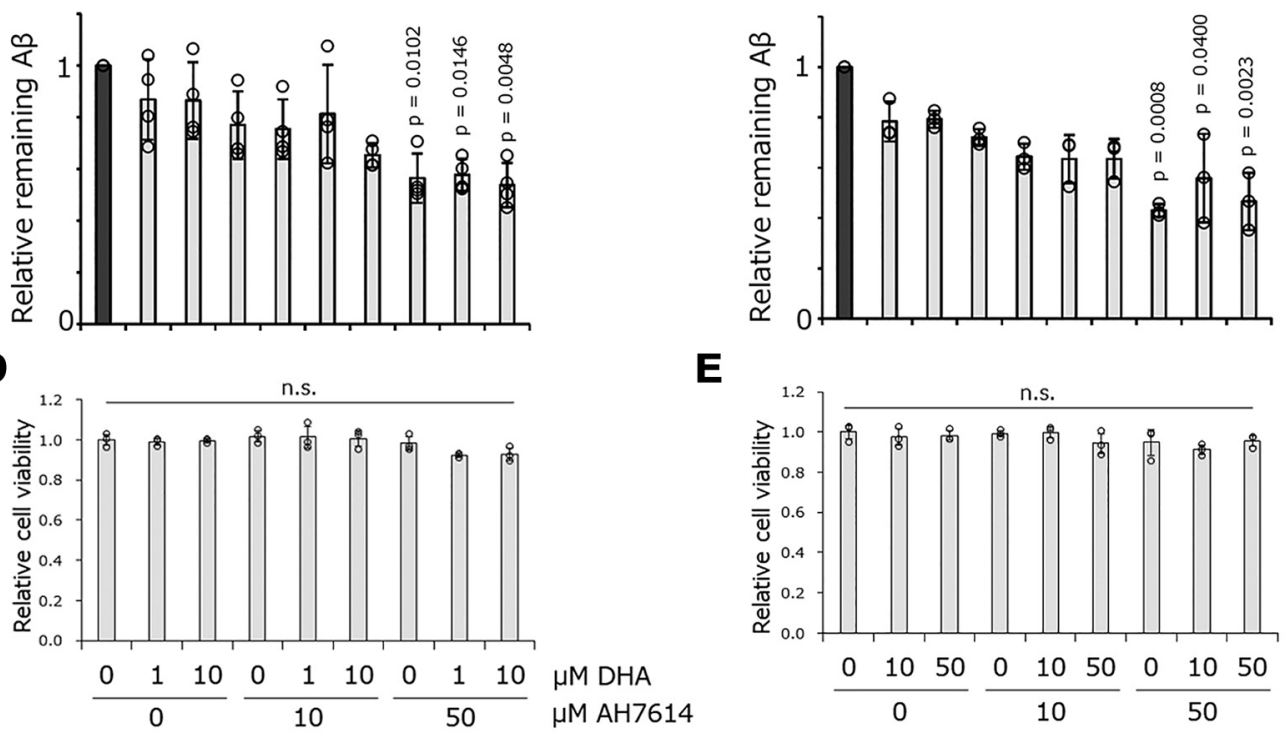

E
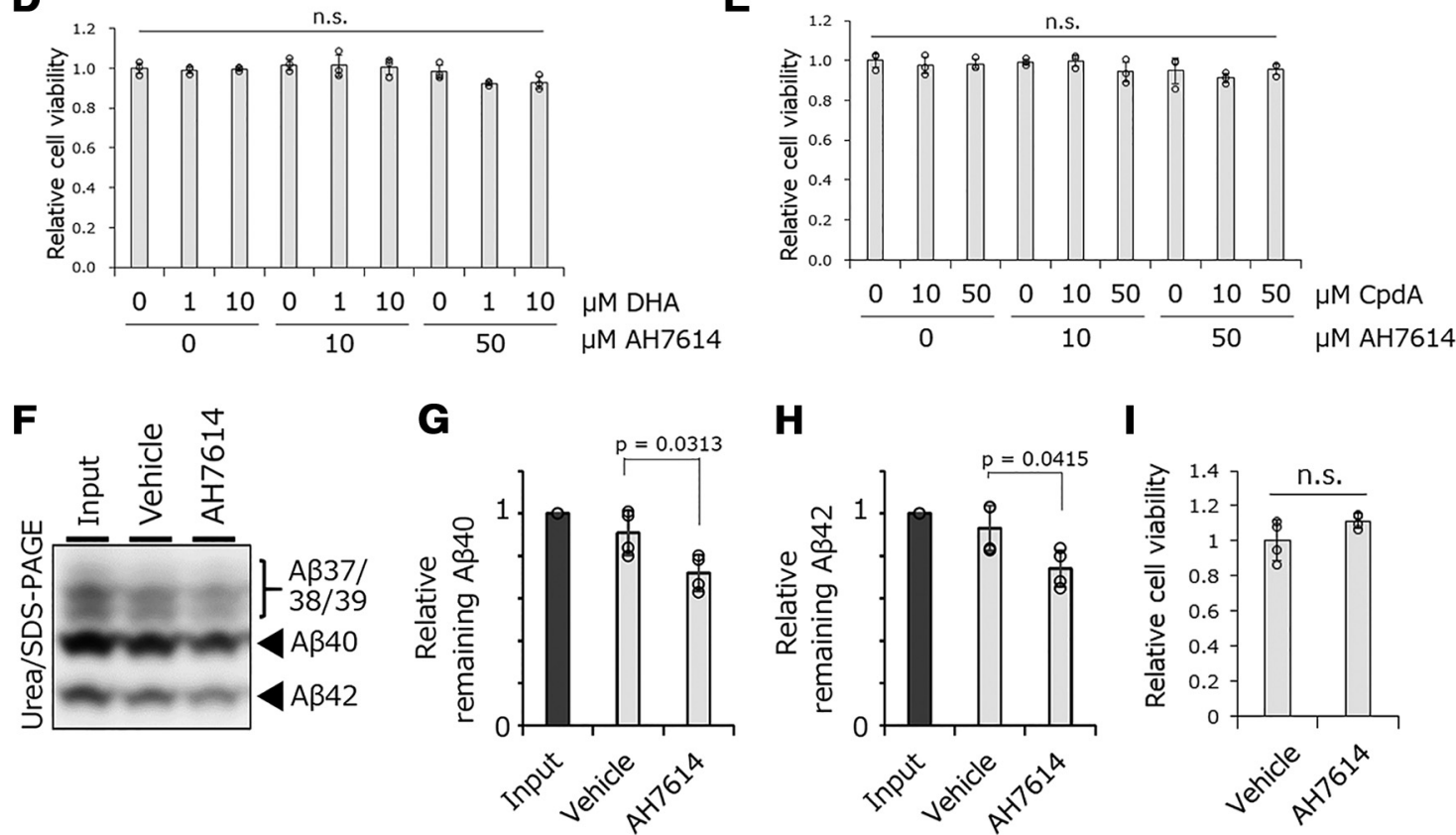

Figure 1. AH7614 treatment induced A $\beta$-degrading activity in primary astrocytes. $A$, Schematic depiction of the $A \beta$-degrading assay. DIV12 to DIV14 primary astrocytes were treated with compounds and $A \beta$ (synthetic $A \beta 40$ or 7PA2 CM) for $48 \mathrm{~h}$. Then, the level of remaining $A \beta$ in the mixture was analyzed by Western blotting. $B$, Degradation of synthetic $A \beta 40$ by primary astrocytes treated with DHA and with or without AH7614. A representative Western blot and quantified results are shown $(n=4$, mean \pm SD, Dunnett test vs $0 \mu$ m DHA). C, Degradation of synthetic $A \beta 40$ by primary astrocytes treated with $\mathrm{CpdA}$, with or without AH7614. Representative Western blot and quantified results are shown $(n=3$, mean $\pm S D$, Dunnett test vs $0 \mu \mathrm{m}$ (pdA). $\boldsymbol{D}$, The cell viability was measured by using alamarBlue under the condition in $\boldsymbol{B}(n=3$, mean $\pm \mathrm{SD}$, Dunnett test vs $0 \mu \mathrm{m}$ DHA). $\boldsymbol{E}$, The cell viability was measured by using alamarBlue under the condition in $C(n=3$, mean \pm SD, Dunnett test vs $0 \mu \mathrm{M}(\mathrm{pdA})$. $\boldsymbol{F}$, Representative Western blot of the remaining level of 7PA2 CM-derived A $\beta$ species after incubation with CM of primary astrocytes treated with AH7614. G, Quantified results of the remaining A $\beta 40$ from 7PA2 cells $(n=4$, mean \pm SD, Student $t$ test vs the Vehicle group). $\boldsymbol{H}$, Quantified results of the remaining $\mathrm{A} \beta 42$ from 7PA2 cells ( $n=4$, mean $\pm \mathrm{SD}$, Student $t$ test vs the Vehicle group). $\boldsymbol{I}$, The cell viability was measured by using alamarBlue under the condition in $\boldsymbol{F}$ - $\boldsymbol{H}$ $(n=4$, mean \pm SD, Student $t$ test vs the Vehicle group).

(https://rnaidesigner.thermofisher.com/rnaiexpress/). The sequence of control shRNA targeting luciferase (shLuci) was designed with reference to the previous report (Lewis et al., 2002). For production of recombinant lentiviral particle, LentiX-293T cells (Takara Bio) were transiently transfected packaging plasmids (pCAG-KGP4.1R, pCAG4-RTR2, and pCAGS-VSVG; a gift from Dr. Haruhiko Bito, The University of Tokyo) with pLKO.1-EGFP containing shRNA sequences using PEI (Okuno et al., 2012; Miyagawa et al., 2016; 
A
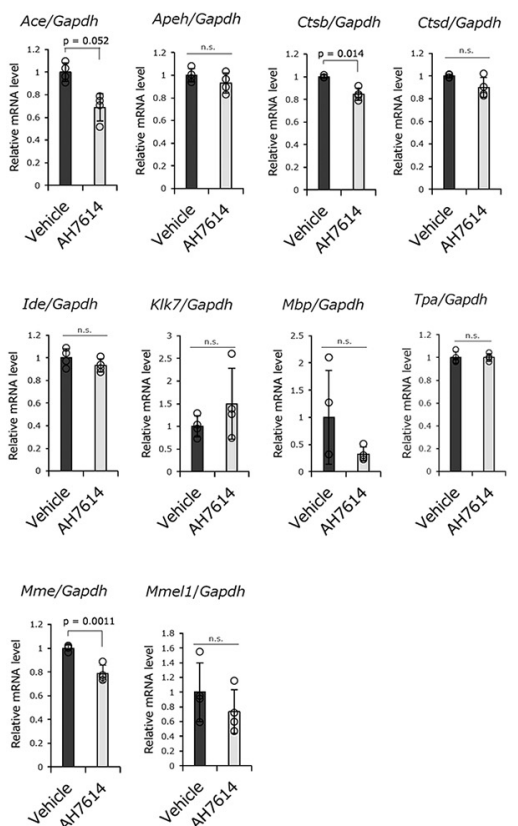

B

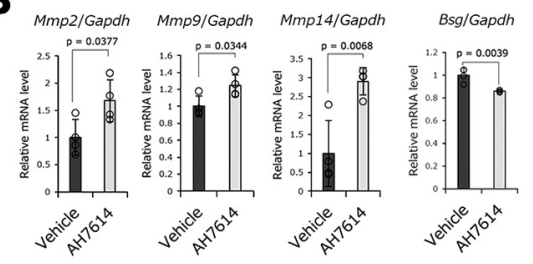

C

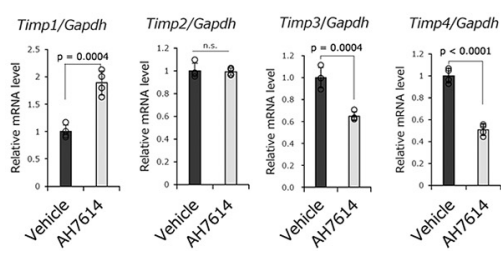

Figure 2. AH7614 treatment affected the expression levels of $A \beta$-degrading enzymes and associated factors. The mRNA expression levels of known $A \beta$-degrading enzymes and their activators $(\boldsymbol{A}, \boldsymbol{B})$ and TIMPS $(C)$ in primary astrocytes treated with $50 \mu \mathrm{m}$ AH7614 and 7PA2 CM for $24 \mathrm{~h}$ were quantified by qRT-PCR $(n=4$, mean \pm SD, Student $t$ test vs the Vehicle group). The mRNA expression of Plau encoding plasminogen, Klk5 encoding kallikrein-related peptidase 5, and Spink5 encoding endogenous inhibitor for KLKs was undetectable in primary astrocytes.

Chiu et al., 2020). After 6 h, medium was refreshed. Thereafter, medium was collected and refreshed daily for $2 \mathrm{~d}$. The lentiviral particle in medium was concentrated using Lenti-X concentrator (Takara Bio, catalog \#631231) and resuspended in DMEM. For knockdown in primary astrocytes, the lentiviral particles were infected at DIV5. Two days after infection, the medium was changed, and the infected cells were cultured for the indicated period.

Animals. All experiments using animals were performed according to the guidelines provided by the Institutional Animal Care Committee of Graduate School of Pharmaceutical Sciences, The University of Tokyo (Protocol P29-30 and P30-3). APP/PS1 mice (B6.Cg-Tg(APPswe, PSEN1dE9)85Dbo/Mmjax, The Jackson Laboratory, JAX mouse \#005864) express a chimeric mouse/human APP with the Swedish mutation $(\mathrm{K} 670 \mathrm{M} / \mathrm{K} 671 \mathrm{~L})$ and human PSEN1 gene with exon 9 deletion under the murine prion promoter (Jankowsky et al., 2004).

Injection of compounds into mice hippocampi. Injection of compounds into mouse hippocampus was performed as described previously (Hori et al., 2015; Kidana et al., 2018). Briefly, $4 \mu \mathrm{l}$ of $100 \mu \mathrm{M}$ AH7614 and 2\% DMSO (vehicle) in PBS, respectively, was injected at $0.3 \mu \mathrm{l} / \mathrm{min}$ into the right and left hippocampus (AP: $-2.0 \mathrm{~mm}$ from bregma, ML: $\pm 1.5 \mathrm{~mm}$ from midline, DV: $-1.7 \mathrm{~mm}$ below brain surface) in 12- to 15 -month-old male APP/PS1 mice $(n=7)$. Twenty-four hours after injection, injected sides of hippocampi were collected from these mice. The change of protein level by AH7614 injection was compared between the left and right hippocampi of individual mice.

Brain extraction and fractionation. Mice hippocampi were homogenized in extraction buffer and centrifuged at $246,200 \times g$ for $20 \mathrm{~min}$ (stepwise). The extraction buffers for each step were the following: first step: TBS, 0.05 м Tris, 0.15 м NaCl, $0.02 \mathrm{tab} / \mathrm{ml}$ cOmplete (Roche), 0.1 $\mathrm{tab} / \mathrm{ml}$ PhosSTOP (Roche), adjusted $\mathrm{pH} 7.6$ by $\mathrm{HCl}$ ); second step: $2 \%$ Triton X-100 in TBS; third step: $2 \%$ SDS in TBS. The $2 \%$ SDS-insoluble fraction was sonicated in $70 \%$ formic acid and centrifuged at $246,200 \times g$ for $20 \mathrm{~min}$. Then, the resultant supernatant was freeze-dried for $2 \mathrm{~h}$ using Savant RVT5105 (Thermo Fisher Scientific). The pellet was dissolved in DMSO. Protein concentration of each fraction was determined by BCA protein assay (Thermo Fisher Scientific).

Data availability. Two public RNAseq datasets were obtained from AMP-AD Knowledge Portal (https://www.synapse.org/\#!Synapse: syn2580853) as previously described (Allen et al., 2016; Wang et al., 2018): the Mayo sample set and Mount Sinai Brain Bank (MSBB) studies. The Mayo study comprises temporal cortex samples from 164 subjects with the following pathologic diagnosis: 84 patients with $\mathrm{AD}$ and 80 controls. We assessed the expression levels of tissue inhibitor of the metalloproteinases 3 (TIMP3), TIMP4, matrix metalloproteinase 2 (MMP2), MMP9, MMP14, and FFAR4 in the temporal cortex between AD patients and controls by a simple model (syn6090804) adjusting for key covariates: age at death, gender, RNA integrity number (RIN), source, and flow cell. For the MSBB study, we obtained clinical information of each subject, RNAseq covariates, and normalized RNA read counts of above targets (syn7391833). As described in the previous report (syn20801188), gene level expression (read counts) was corrected for known covariates factors, including postmortem interval, race, batch, sex, RIN, and exonic rate to remove the confounding effects. The trimmed mean of $\mathrm{M}$ values normalization method was used to estimate scaling factors and adjust for differences in library sizes. We selected 201 samples of the parahippocampal gyrus (Brodmann area 36) from subjects and excluded the samples without the information of the Braak NFT stage. These data were applied and analyzed using Python Jupyter Notebook. The comparison of expression levels of TIMP3, TIMP4, MMP2, MMP9, MMP14, and FFAR4 was performed among different categories described as follows: We divided samples into two categories, healthy control subjects and AD patients, depending on the NP.1 stage, neuropathology category as measured by CERAD.

Statistical analysis. Data are presented as mean values, and error bars indicate SD. For data analysis, paired $t$ test, Student's $t$ test, Tukey test, and Dunnett test were performed using KyPlot (KyensLab) or Excel (Microsoft) software. For analysis of RNAseq datasets, Mann-Whitney $U$ test, Kruskal-Wallis test with Dunn's post hoc analysis, and Kendall rank correlation were performed to compare the gene expression levels. A $p$ value $<0.05$ was considered to have a significant difference.

\section{Result}

Treatment of GPR120-selective antagonist upregulated the A $\beta$-degrading activity of primary astrocytes GPR120 is abundantly expressed in the gastrointestinal tract (Hirasawa et al., 2005). Recent analyses demonstrated that GPR120 is also expressed in the brain (Dragano et al., 2017; Ren et al., 2019). We also confirmed the expression of endogenous GPR120 in primary glial cells, mainly comprised of astrocytes (see below in Fig. $3 D$ ). To investigate whether GPR120 signaling affects the $\mathrm{A} \beta$-degrading activity of astrocytes, we analyzed the effects of DHA, the GPR120- 
A

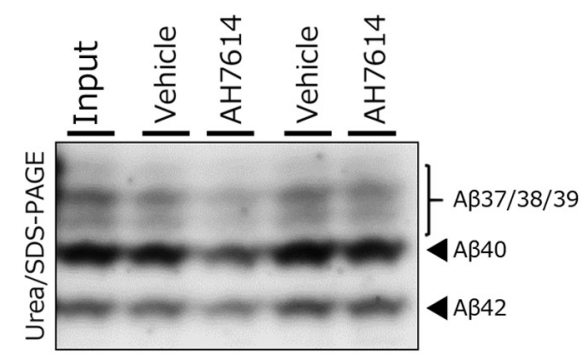

B

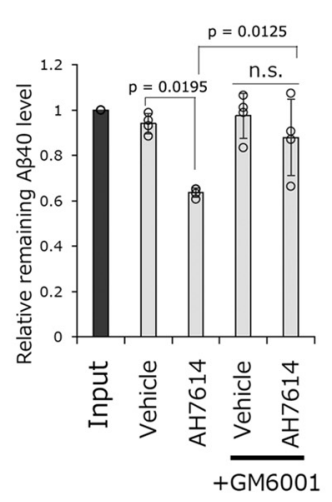

C

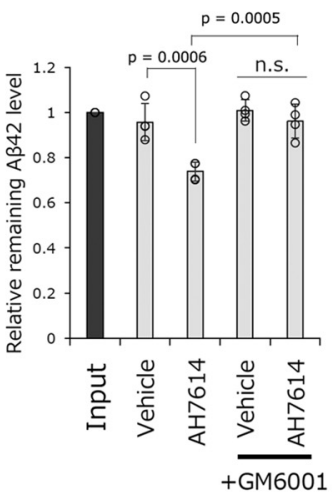

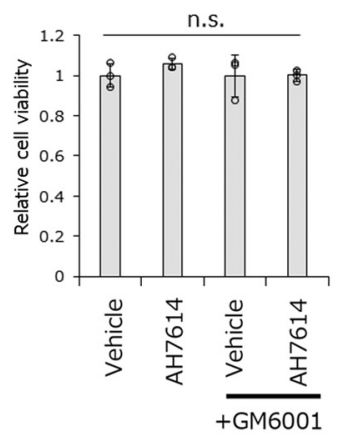

$\mathbf{F}$

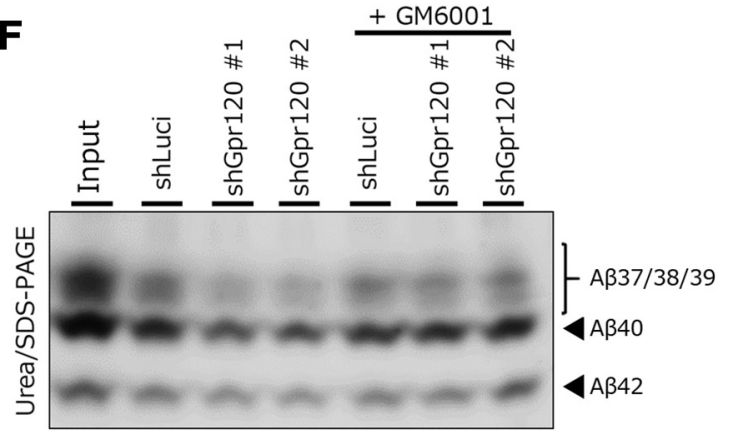

Gpr120/Gapdh

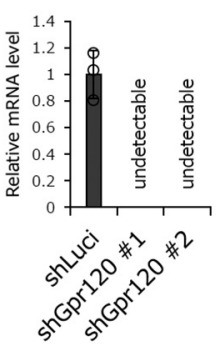

E

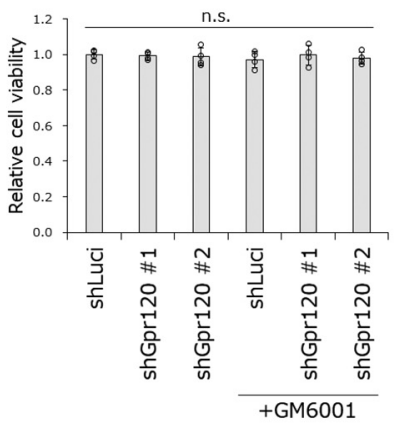

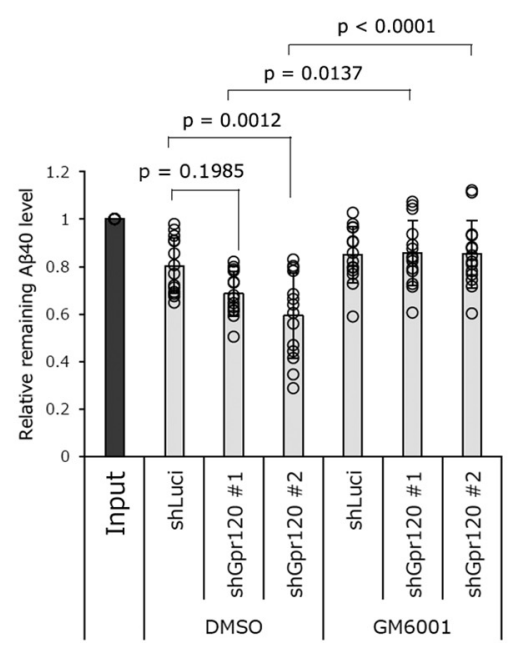

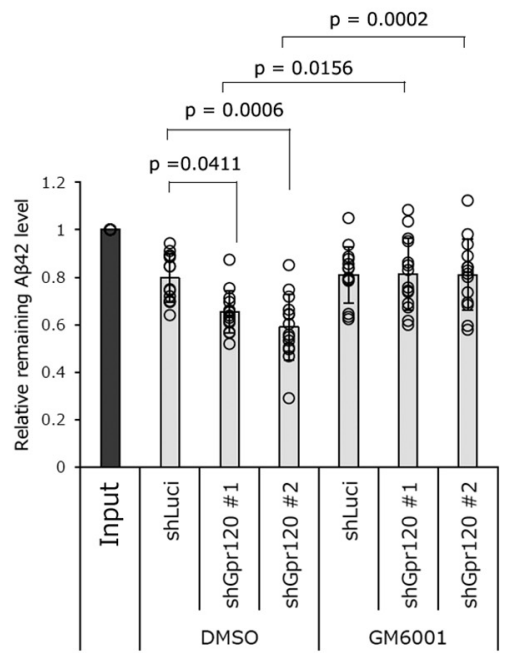

Figure 3. GM6001 treatment abolished the $A \beta$-degrading activity induced by suppression of GPR120 signaling. $A$, Representative Western blot of the remaining levels of 7PA2 CM-derived $\mathrm{A} \beta 40$ and $\mathrm{A} \beta 42$ in the mixture of $\mathrm{CM}$ from primary astrocytes treated with $50 \mu \mathrm{m} A \mathrm{AH} 7614$ with or without $25 \mu \mathrm{m} \mathrm{GM6001} \mathrm{for} 48 \mathrm{~h}$. $B$, Quantified results of the remaining $A \beta 40$ and $\mathrm{A} \beta 42$ in $\boldsymbol{A}(n=4$, mean $\pm S D$, Tukey test). C, The cell viability was measured by using alamarBlue under the condition in $\boldsymbol{A}, \boldsymbol{B}$ ( $n=3$, mean \pm SD, Tukey test). $\boldsymbol{D}$, Seven days after infection of lentiviral shRNAs for luciferase (shLuci) or two different target sequences in Gpr120 (shGpr120 \#1 or \#2), Gpr120 expression levels in primary astrocytes were quantified by qRT-PCR ( $n=3$, mean $\pm S D$, Dunnett test vs the shLuci group). $\boldsymbol{E}$, The cell viability was measured by using alamarBlue under the condition in $\boldsymbol{F}, \boldsymbol{G}(n=4$, mean \pm SD, Tukey test). $\boldsymbol{F}$, At DIV12, Gpr120-knockdown primary astrocytes were treated with 7PA2 CM and with or without $25 \mu \mathrm{m}$ GM6001. After $96 \mathrm{~h}$, the remaining level of 7PA2 CM-derived $A \beta 40$ and $A \beta 42$ in CM was quantified by Western blotting. $\mathbf{G}$, Quantified results of $\boldsymbol{F}(n=14$, mean \pm SD, Tukey test).

selective agonist compound A (CpdA) (Oh et al., 2014), and the GPR120-selective antagonist AH7614 (Sparks et al., 2014; Watterson et al., 2017) on the A $\beta$-degrading assay using synthetic human A $\beta 40$ (Kidana et al., 2018) (Fig. 1A). Although treatment with DHA or CpdA showed no effects, treatment with AH7614 significantly decreased the levels of remaining $\mathrm{A} \beta$ in the $\mathrm{CM}$ (Fig. $1 B, C$ ) without affecting the cell viability (Fig. $1 D, E$ ). Moreover,
AH7614 treatment significantly enhanced the degrading activity of astrocytes for various $\mathrm{A} \beta$ species in the $\mathrm{CM}$ of 7PA2 cells, which stably express mutant human APP and secrete a robust amount of several A $\beta$ species (Podlisny et al., 1995) (Fig. $1 F-I$ ). These results suggested that the inhibition of GPR120 in astrocytes upregulated the degrading activity of not only synthetic $\mathrm{A} \beta$, but also naive $\mathrm{A} \beta$ species secreted from the cultured cells. 
A

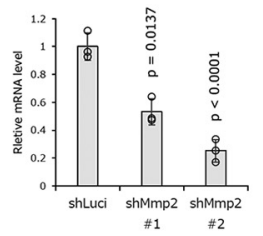

B

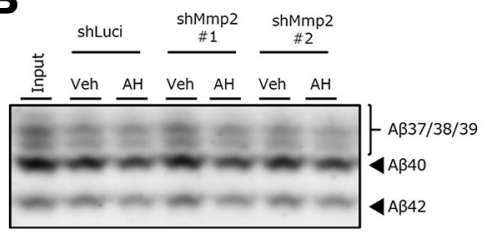

D

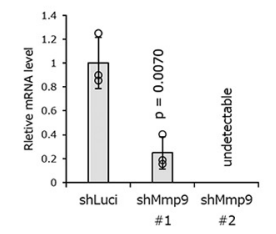

E

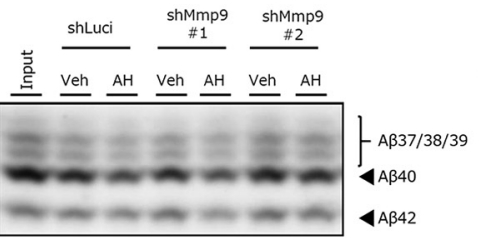

G

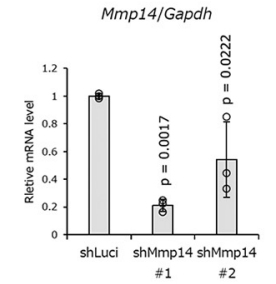

H

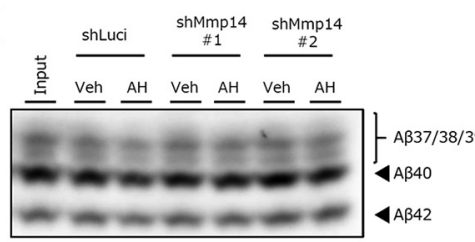

J

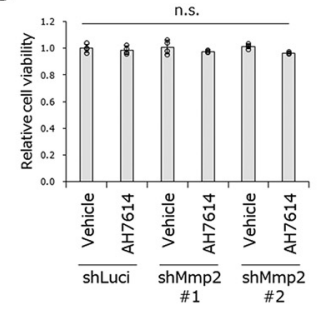

C

$\mathbf{F}$

】
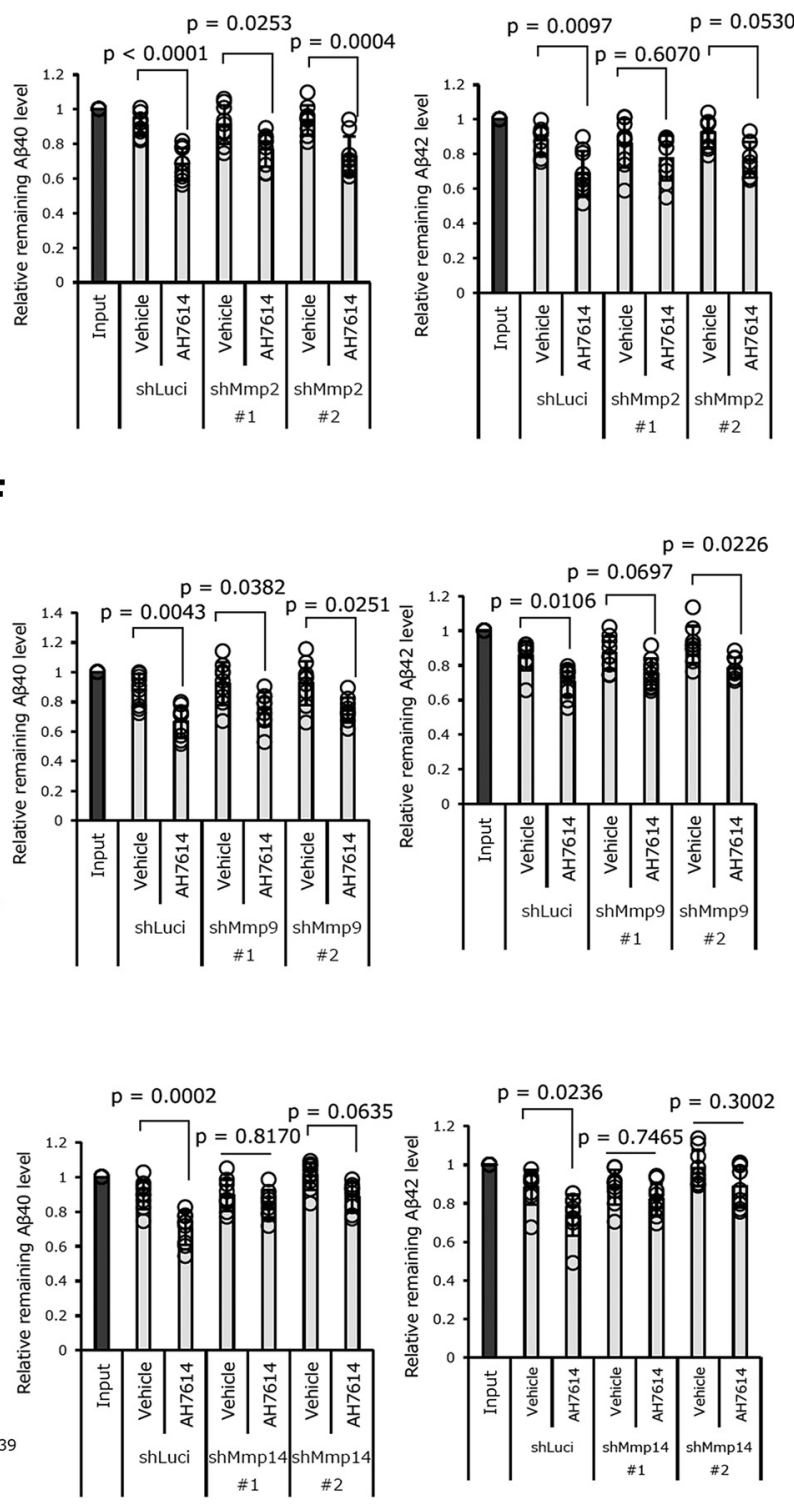

Figure 4. MMP14 knockdown, but neither MMP2 nor MMP9 knockdown, suppressed the A $\beta$-degrading activity induced by AH7614 treatment. Seven days after infection of lentiviral shRNAs targeting luciferase, Mmp2 (A-C), Mmp9 (D- $\boldsymbol{F})$, and Mmp14 (G-I) into primary astrocytes, mRNA expression levels were quantified by qRT-PCR $(n=3$, mean \pm SD, Dunnett test vs shLuci group) $(A, D, G)$. At DIV12, the infected primary astrocytes were treated with 7PA2 CM and with $50 \mu \mathrm{m}$ AH7614 for $48 \mathrm{~h}$. Then, the remaining levels of 7PA2 CM-derived A $\beta 40$ and $\mathrm{A} \beta 42$ in the $C M$ of each sample were analyzed by Western blotting $(\boldsymbol{B}, E, H) . C, F, I$, Quantified results $(n=9$, mean $\pm S D$, Tukey test). The cell viability was measured by using alamarBlue under the condition in $\boldsymbol{B}, \boldsymbol{C}(\boldsymbol{J}, n=4$, mean $\pm S D$, Tukey test), in $\boldsymbol{E}, \boldsymbol{F}(\boldsymbol{K}, n=4$, mean $\pm S D$, Tukey test), and in $\boldsymbol{H}, \boldsymbol{I}(\boldsymbol{L}, n=4$, mean \pm SD, Tukey test).

\section{GPR120 regulated the $A \beta$-degrading activity regulated by} MMP14

Next, we analyzed the expression levels of mRNAs of known degrading enzymes for extracellular $\mathrm{A} \beta$ in AH7614-treated primary astrocytes (Saido and Leissring, 2012; Ries and Sastre, 2016; Kidana et al., 2018). No change was observed in the expression level of Apeh (Yamin et al., 2007), Ctsd (Hamazaki, 1996; McDermott and Gibson, 1996), Ide (Qiu et al., 1998), Klk7 
Table 3. Mayo RNAseq cohort shows the changes in FFAR4, MMP2, MMP9, MMP14, TIMP3, and TIMP4 mRNA levels in AD patients ${ }^{a}$

\begin{tabular}{lcll}
\hline Gene name & Dx $\beta$ & Effect direction & Dx q \\
\hline FFAR4 & -1.175087753 & Down in AD & $3.12 \mathrm{E}-06$ \\
MMP2 & 0.393271813 & Up in AD & 0.060226773 (ns) \\
MMP9 & 0.93970622 & Up in AD & 0.004726111 \\
MMP14 & 0.836293303 & Up in AD & 0.000186216 \\
TIMP3 & 0.900172204 & Up in AD & $3.66 \mathrm{E}-06$ \\
TIMP4 & 0.261013671 & Up in AD & 0.227104156 (ns) \\
\hline
\end{tabular}

${ }^{a}$ Comparison of the FFAR4, MMP2, MMP9, MMP14, TIMP3, and TIMP4 mRNA levels from 80 control and 84 AD subjects. Normalized read counts of mRNAs were assessed by the simple model considering the factors, including age at death, gender, RIN, source, and flow cell. Dx $\beta$ indicates the regression coefficient. Effect direction indicates the changes in target mRNA level between control and AD patients. Dx $q$ indicates the adjusted $p$ value with a significant difference when $\operatorname{Dx} q<0.05$.

(Kidana et al., 2018), Mbp (Liao et al., 2009), Mmel1 (Shirotani et al., 2001), or Tpa (Van Nostrand and Porter, 1999) mRNA (Fig. 2A). In addition, levels of Ace (Hu et al., 2001) and Mme (Shirotani et al., 2001) mRNAs were significantly decreased (Fig. $2 A)$. In contrast, AH7614 treatment increased the mRNA levels of the A $\beta$-degrading MMPs Mmp2 (Roher et al., 1994), Mmp9 (P. Yan et al., 2006), and Mmp14 (Liao and Van Nostrand, 2010) (Fig. 2B). We also found that the expression levels of Timp3 and Timp4 mRNAs, which encode TIMP3 and TIMP4, respectively, were decreased by AH7614 treatment (Fig. 2C). In contrast, the expression of $B s g$, encoding extracellular MMP inducer, was decreased (Agrawal and Yong, 2011) (Fig. 2B). These data suggested that AH7614 regulated the expression of a variety of genes in astrocytes. Among them, we focused on the activities of MMPs, which are $\mathrm{A} \beta$-degrading enzymes that demonstrated increased activity by AH7614 treatment. Supporting this notion, GM6001, a broad-spectrum MMP inhibitor, abolished the A $\beta$ degrading activity induced by AH7614 without affecting the cell viability (Fig. $3 A-C$ ). Then, we analyzed the effects of the knockdown of GPR120 in astrocytes by a recombinant lentivirus expressing shRNA targeting Ffar4, which encodes GPR120 (Fig. $3 D)$. We confirmed that $\mathrm{A} \beta$-degrading activity in primary astrocytes was significantly increased by Ffar4 knockdown without any cell toxicity, and this activity was inhibited by GM6001 treatment (Fig. 3E-G). Thus, GPR120 signaling negatively controlled the $\mathrm{A} \beta$-degrading activity of MMP family proteins in astrocytes.

Among the A $\beta$-degrading MMPs, MMP2 and MMP9 are secreted MMPs, whereas MMP14/MT1-MMP is a membranetethered protease (Beroun et al., 2019; Rivera et al., 2019). MMP2 and MMP9 have similar substrate preferences to gelatinases. MMP14 is known as collagenase and activates MMP2 by cleaving the prodomain of MMP2 on the cell surface. Moreover, TIMP3 is an effective inhibitor of MMP14, suggesting the complexity and redundant nature of MMPs. To clarify which MMP activity is crucial for GPR120-regulated $\mathrm{A} \beta$-degrading activity, we analyzed $\mathrm{A} \beta$ degradation by primary astrocytes infected with a recombinant lentivirus expressing shRNA against each MMP. We found that knockdown of neither $M m p 2$ (Fig. 4A-C,J) nor $M m p 9$ (Fig. $4 D-F, K$ ) affected AH7614-induced A $\beta$ degradation. In contrast, Mmp14 RNAi abolished the effects of AH7614 without any cell toxicity (Fig. $4 G-I, L$ ). These results indicated that the inhibition of GPR120 signaling upregulated the MMP14-dependent $\mathrm{A} \beta$-degrading activity.

We further analyzed the expression profiles of FFAR4, MMP2, MMP9, MMP14, TIMP3, and TIMP4 mRNAs in AD brains using two public RNAseq datasets deposited in the accelerating medicines partnership-Alzheimer's disease (AMP-AD) knowledge portal, namely, the Mayo RNAseq (MayoRNAseq) and MSBB AD cohorts (Allen et al., 2016; Wang et al., 2018). In the Mayo sample set, we found that the levels of TIMP3, MMP9, and MMP14 mRNA were increased in the temporal cortex of $\mathrm{AD}$ patients (Table 3). In contrast, FFAR4 mRNA level was significantly decreased. Consistent with this, in the analysis of the MSBB, we confirmed the increased expression level of $M M P 14$, whereas the level of FFAR4 mRNA was significantly decreased in Brodmann area 36 of $\mathrm{AD}$ patients, including in the parahippocampal gyrus (Fig. 5A). Furthermore, we found that FFAR4 mRNA levels negatively correlated with MMP14 mRNA levels (Fig. 5B). Collectively, these data strengthen our findings that the downregulation of GPR120 signaling in astrocytes is associated with the increased expression of $\mathrm{A} \beta$-degrading MMP proteins, and thus with its involvement in $\mathrm{AD}$ pathology.

\section{Intracerebral injection of GPR120-selective antagonist upregulated A $\beta$-degrading activity by MMP in AD model mice}

As the brain contains high concentrations of $\omega 3$ PUFAs, GPR120 signaling is expected to be constitutively activated in the brain. The in vitro experiments described above prompted us to investigate whether the inhibition of GPR120 in vivo effectively reduces brain A $\beta$ levels. To test this, AH7614 was injected into the right hippocampus of 12- to 15-month-old APP/PS1 mice, which coexpress mutant APP and presenilin 1 (Jankowsky et al., 2004) (Fig. 6A). A $\beta$ deposition in these mice starts from $\sim 6$ months old and reaches a plateau at 12 months old (Minkeviciene et al., 2008; Jackson et al., 2013). Twentyfour hours after injection, hippocampi were fractionated into the TBS-soluble fraction, Triton X-100-soluble fraction, SDS-soluble fraction, and SDS-insoluble fraction. Then, the A $\beta$ level in each fraction was analyzed. TBS-soluble A $\beta$ levels in AH7614-injected hippocampi were significantly decreased by $\sim 30 \%$ (Fig. $6 B, C$ ). The Triton X-100-soluble fraction contained no detectable $\mathrm{A} \beta$. A $\beta$ levels in the SDS-soluble fraction and SDS-insoluble fraction were unchanged by AH7614 injection (Fig. $6 D, E$ ). In addition, AH7614 injection showed no effects on the protein levels of APP, BACE1, $\operatorname{SAP} \beta$, and C99, indicating that the $\mathrm{A} \beta$ production machinery was not altered by the inhibition of GPR120 signaling (Fig. $6 F$ ). Moreover, the coinjection of GM6001 with AH7614 abolished the induced A $\beta$ degradation in the APP/PS1 mouse brain in a similar manner to that observed in primary astrocytes (Fig. $6 G$ ). These results indicated that the inhibition of GPR120 signaling in the brains of APP/PS1 mice upregulates the MMP-mediated degradation of soluble $\mathrm{A} \beta$.

\section{Discussion}

In this study, we found that inhibition of GPR120 signaling in astrocytes increased $A \beta$ degradation by MMP proteins (Fig. 7). Both antagonist treatment and RNAi experiments augmented A $\beta$-degrading activity, which was sensitive to the pan-MMP inhibitor GM6001. Importantly, knockdown of Mmp14, which is an $\mathrm{A} \beta$-degrading protease and activator of other MMPs, abolished the AH7614-induced A $\beta$ degradation. Moreover, expression levels of MMP14 and FFAR4, the latter encoding GPR120, were negatively correlated in the human brain. Finally, we demonstrated that the inhibition of GPR120 signaling in the brains of $\mathrm{AD}$ model mice significantly reduced $\mathrm{A} \beta$ levels, suggesting that GPR120 signaling functionally regulates MMP-mediated proteolytic activities against $\mathrm{A} \beta$ in vivo. 
A
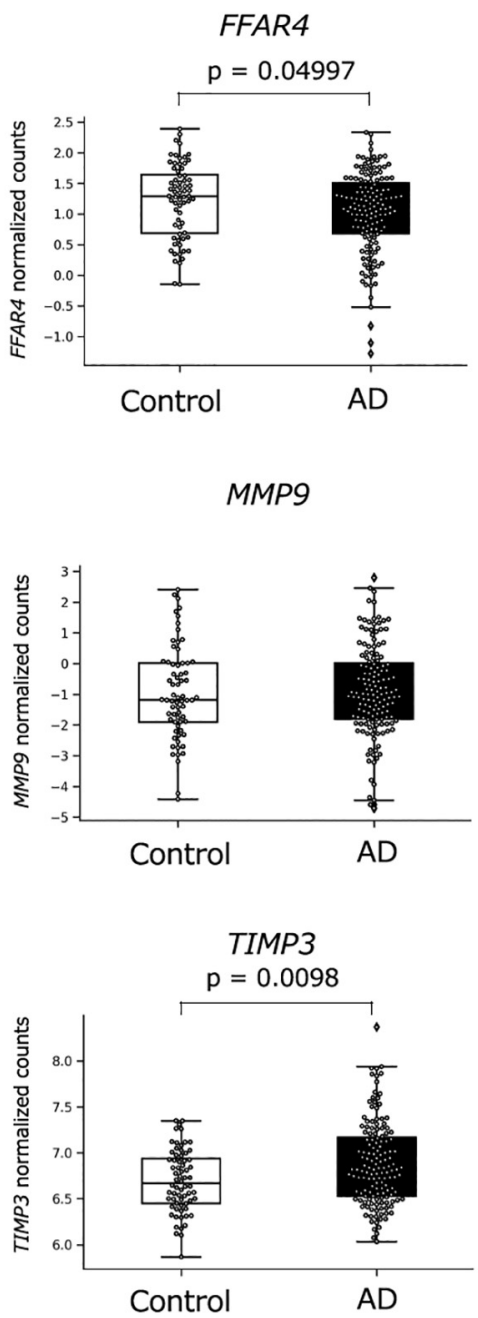
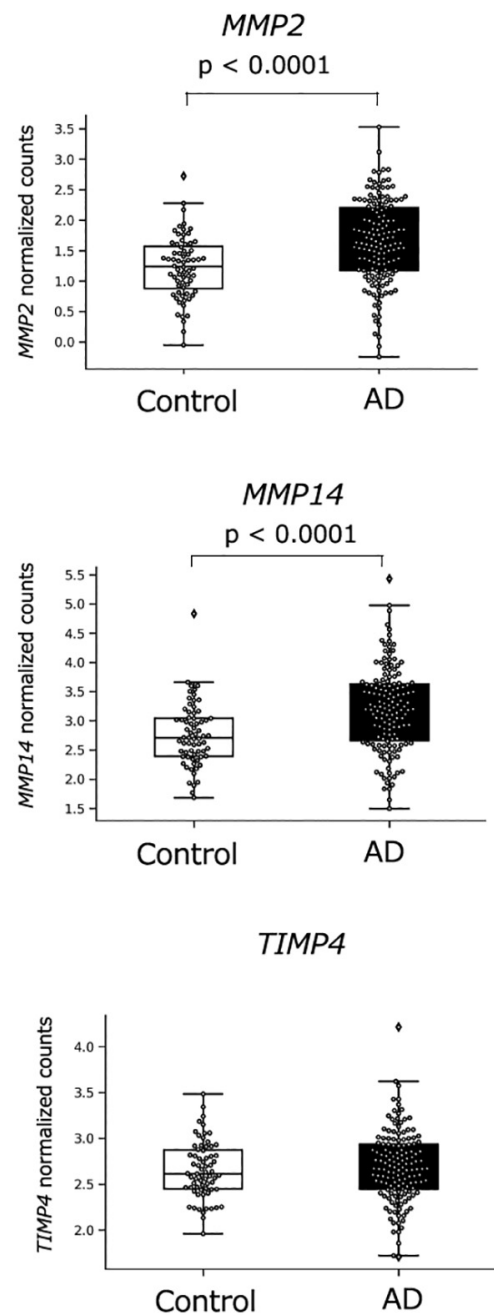

B

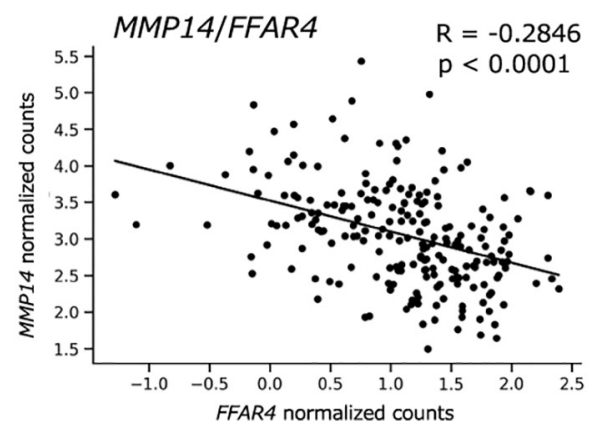

Figure 5. Changes in the expression levels of FFAR4, MMP2, MMP9, MMP14, TIMP3, and TIMP4 in AD patients. A, Healthy control subjects (Control) were defined as those in whom neuropathology measured by CERAD was equal to $1(n=64)$. AD patients were the other subjects in whom neuropathology ranged from 2 to $4(n=137)$. FFAR4 mRNA levels were significantly decreased in AD patients. On the other hand, MMP2, MMP14, and TIMP3 mRNA levels were significantly increased in AD patients. $p$ values were calculated by the Mann-Whitney $U$ test. $\boldsymbol{B}$, FFAR4 mRNA levels negatively correlated with MMP14 mRNA levels from 201 subjects. Line indicates the regression line. The correlation coefficient and $p$ value were assessed from the Kendall rank correlation coefficient.

In peripheral organs, including adipose tissue, GPR120 is the functional receptor for $\omega 3$ PUFAs, leading to robust anti-inflammatory and insulin-sensitizing effects (Oh and Olefsky, 2016). Genetic ablation of the Ffar4 gene led to obesity in mice, and genetic variants of the FFAR4 gene have been identified in subjects with obesity and diabetes (Ichimura et al., 2012). However, the role of GPR120 in the brain remains unclear, although
TIMP4

several types of brain cells have been shown to express Ffar4 mRNA (Ren et al., 2019). Our study shows that GPR120mediated signaling in astrocytes negatively regulates proteolytic activities by regulation of the expression of several MMPs and TIMPs. As $\omega 3$ PUFAs are enriched in the brain, these proteolytic activities in astrocytes are thought to be constitutively suppressed in the brain. Intriguingly, several reports suggest that, in peripheral tissues, increased level of $\omega 3$ PUFAs suppress the expression and activity of MMPs, which are involved in the remodeling of extracellular matrices (Taguchi et al., 2014; Yun et al., 2016; Zhang et al., 2016). Thus, the constitutive inhibition of MMP activities via GPR120 signaling maintains the microenvironment of the brain (Beroun et al., 2019; Rivera et al., 2019). However, under pathologic conditions, decreased level of $\omega 3$ PUFAs might initiate the structural and functional remodeling of the brain microenvironment by the upregulation of MMP activities in astrocytes.

MMP2, MMP9, and MMP14 are known as $\mathrm{A} \beta$-degrading proteases (Roher et al., 1994; P. Yan et al., 2006; Liao and Van Nostrand, 2010). Knockdown experiments demonstrated that MMP14 is a crucial enzyme for the AH7614-induced degradation of $\mathrm{A} \beta$, although $\mathrm{AH} 7614$ treatment altered the expression of multiple MMPassociated genes, including $M m p 14, M m p 2$, $M m p 9$, Timp3, and Timp4 in primary astrocytes. The molecular mechanism by which GPR120 signaling controls the expression of multiple MMPs and TIMPs remains unclear. Bsg pathway has been known to induce the expression of MMPs (Agrawal and Yong, 2011), while the inhibition of GPR120 signaling decreased the Bsg level in this study (Fig. 2B). Of note, The opposite expression control of MMPs and TIMPs by NF- $\kappa$ B has been reported in tumor metastasis and fibrosis models (Yun et al., 2016). Supporting this notion, GPR120 regulates inflammatory responses in various cells via the NF- $\kappa \mathrm{B}$ pathway (Oh and Olefsky, 2016; Han et al., 2017). Thus, AH7614 appears to induce proinflammatory responses in astrocytes to augment MMP activities. As MMP14 activates MMP2 and MMP13, the latter further cleaving the prodomain of MMP9, MMP14 is a key enzyme in GPR120-regulated $\mathrm{A} \beta$ degradation.

Expression analysis of human brain samples further strengthened our observation in vitro; that is, the expression levels of MMP14 negatively correlated with FFAR4 mRNA levels, supporting our notion that GPR120 signaling regulates MMP14 expression in the human brain. However, unexpectedly, we found that the expression levels of FFAR4 mRNA were 
A

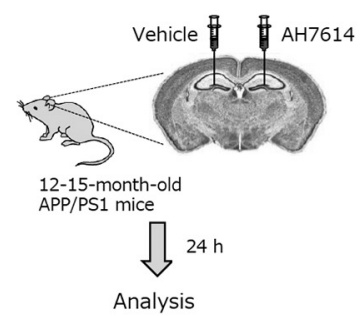

B

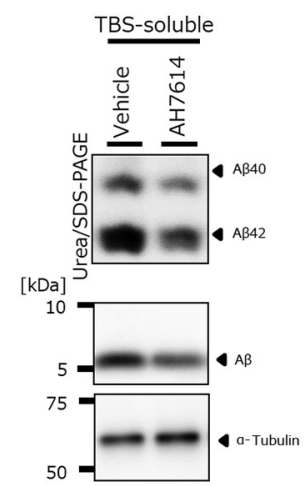

C
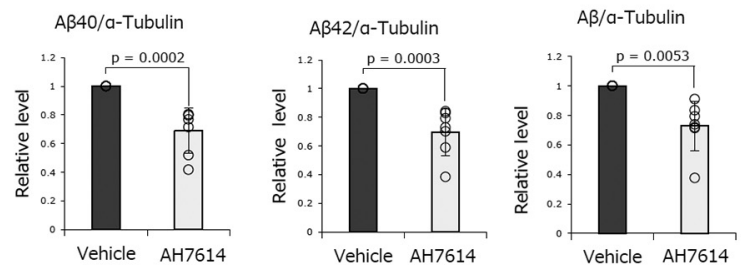

D
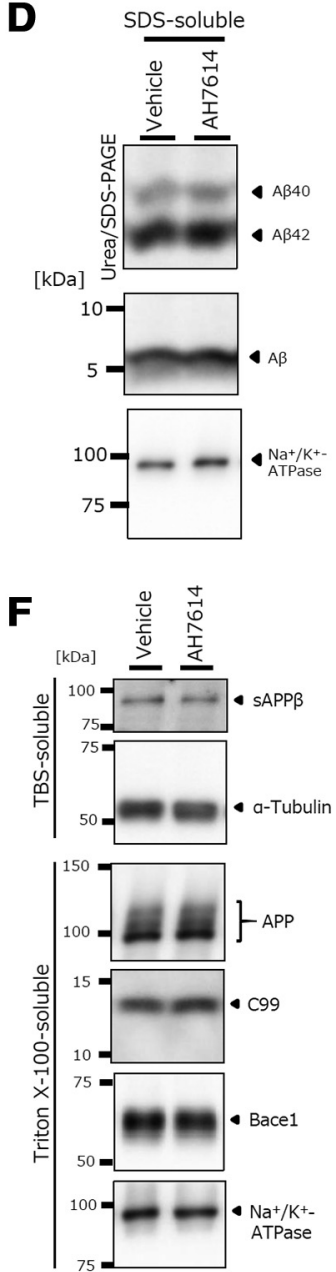

A $340 / \mathrm{Na}^{+} \mathrm{K}^{+}-$-ATPase

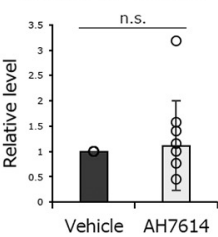

$\mathrm{AB} / \mathrm{Na}^{+} \mathrm{K}^{+}$-ATPase

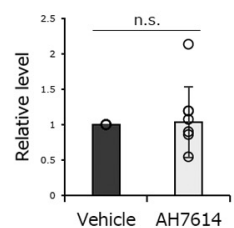

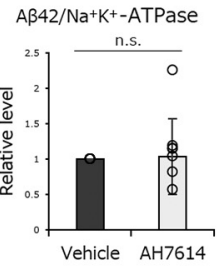

E
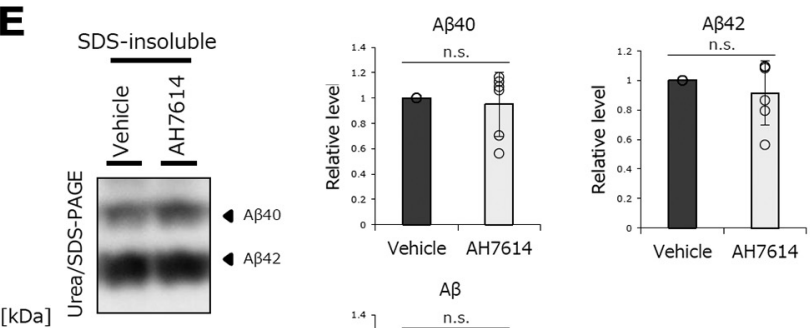

G
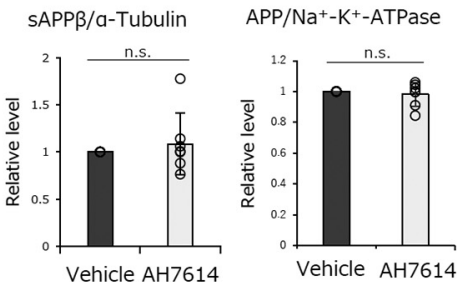

C99/ $\mathrm{Na}^{+}-\mathrm{K}^{+}$-ATPase

Bace1/Na-K+-ATPase
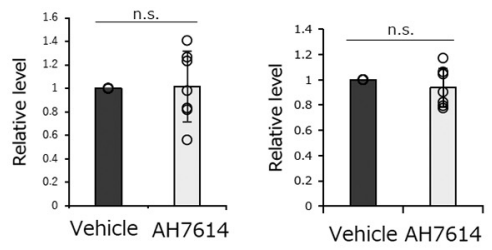
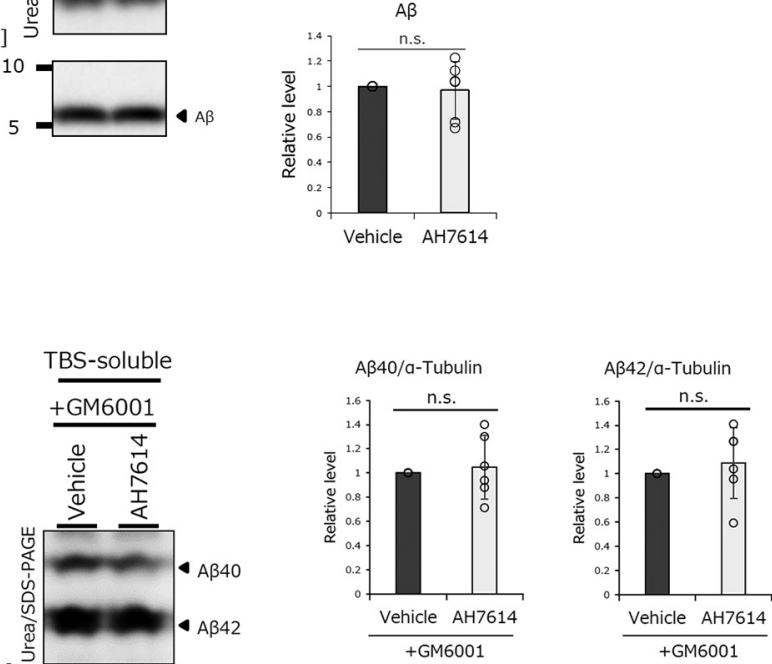

A $/$ a-Tubulin

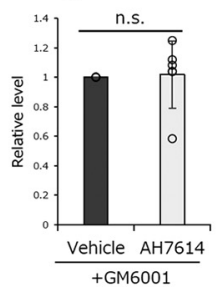

Figure 6. Administration of AH7614 reduced soluble A $\beta$ levels in APP/PS1 mice. $A, A$ schematic representation of the in vivo injection experiments. AH7614 (100 $\mu$ m) was injected into the right hippocampus, and vehicle was injected into the left hippocampus of 12- to 15-month-old APP/PS1 mice. Twenty-four hours after the injection, hippocampi were collected and analyzed after sequential fractionation. $B, A$ representative Western blot of $A \beta 40, A \beta 42$, total $A \beta$, and $\alpha$-tubulin levels in the TBS-soluble fraction of hippocampi injected with or without AH7614. $\boldsymbol{C}$, Quantified results of $\boldsymbol{B}(n=7$, mean $\pm \mathrm{SD}$, paired $t$ test). $\boldsymbol{D}$, A representative Western blot and quantified results of $A \beta 40, A \beta 42$, total $A \beta$, and $\alpha$-tubulin levels in SDS-soluble fractions of hippocampi injected with or without AH7614 ( $n=7$, mean $\pm \mathrm{SD}$, paired $t$ test). $\boldsymbol{E}$, A representative Western blot and quantified results of A $\beta 40, \mathrm{~A} \beta 42$, total A $\beta$, and $\alpha$-tubulin levels in SDS-insoluble fractions of hippocampi injected with or without AH7614 ( $n=6$, mean \pm SD, paired $t$ test). $\boldsymbol{F}$, Expression levels of sAPP $\beta$, $\alpha$-tubulin (TBS-soluble fraction), APP, C99, Bace1, and $\mathrm{Na}^{+} / \mathrm{K}^{+}$-ATPase (Triton X-100-soluble fractions) in fractionated hippocampi injected with or without AH7614 analyzed by Western blotting ( $n=7$, mean \pm SD, paired $t$ test). $\mathbf{G}, \mathrm{A}$ representative Western blot and quantified results of $\mathrm{A} \beta 40, \mathrm{~A} \beta 42$, total $\mathrm{A} \beta$, and $\alpha$-tubulin levels in TBS-soluble fractions of hippocampi injected with or without AH7614 together with $50 \mu \mathrm{m}$ GM6001 ( $n=6$, mean \pm SD, paired $t$ test).

significantly decreased in the brains of $\mathrm{AD}$ patients. Then, why do these patients develop $\mathrm{AD}$ pathology, including $\mathrm{A} \beta$ deposition? The most prominent difference in MMP/TIMP expression profiles was the increased expression of TIMP3 in AD brains, whereas AH7614-treated astrocytes showed reduced Timp3
mRNA levels. One possible explanation of this difference is the regulation by other molecules independent of GPR120 signaling pathway, such as transcriptional factor Sp1. Some reports suggested that $\mathrm{Sp} 1$ activated the Timp3 expression (Qureshi et al., 2005; D. Yan et al., 2013), and the expression level of Sp1 was 


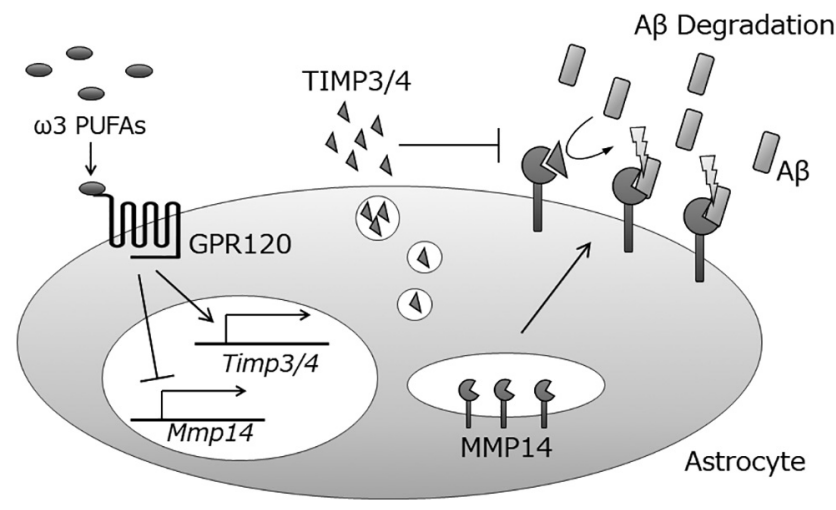

Figure 7. GPR120 signaling negatively regulates the $A \beta$-degrading activity in the astrocytes. Astrocytic GPR120 signaling suppressed the $A \beta$-degrading activity by regulating the expression levels of MMP14 and TIMP3/TIMP4.

increased in $\mathrm{AD}$ brain (Citron et al., 2008). Moreover, the pathologic effects of neurodegeneration in the AD brain, as well as cell-type differences, might affect the expression of MMP-associated genes, including TIMP3, as FFAR4 expression was observed in multiple cells in the brain (Ren et al., 2019). Nevertheless, further genetic analyses together with single-cell technology are required for the precise understanding of the importance of GPR120 signaling in the regulation of MMPs and TIMPs in the AD brain.

Finally, we determined the possibility of GPR120 as a therapeutic target via an anti-A $\beta$ approach using the APP/PS1 mouse model, in which the expression level of Ffar4 mRNA is maintained after the development of $\mathrm{A} \beta$ plaques. The pharmacological inhibition of GPR120 signaling by the injection of AH7614 reduced the levels of soluble $\mathrm{A} \beta$ by $30 \%$ without affecting the expression of APP, BACE1, and $\gamma$-secretases (Fig. 6). However, the global inhibition of GPR120 is known to lead to obesity (Ichimura et al., 2012), and a GPR120-selective agonist was shown to improve insulin resistance (Oh et al., 2014). Intriguingly, GPR120 mediates multiple signaling pathways via distinct molecular mechanisms (Oh and Olefsky, 2016; Milligan et al., 2017). Metabolic control by GPR120-mediated incretin release was dependent on the Gq/G11 G-protein family and increased levels of intracellular calcium ions (Hirasawa et al., 2005). GPR120 also initiates the $\beta$-arrestin-mediated anti-inflammatory signals to attenuate NF- $\kappa$ B activation in immune cells (Watson et al., 2012; Han et al., 2017), the latter being involved in the expression of MMPs and TIMPs, suggesting the heterogeneity of GPR120 signaling in a cell- and/or context-dependent manner. Thus, further investigation of the signaling mechanism by which GPR120 inhibition in astrocytes increases $\mathrm{A} \beta$-degrading activity at the molecular level would provide a novel therapeutic target for AD. Collectively, these results indicate that the inhibition of GPR120 signaling strongly affects $\mathrm{A} \beta$ economy in the brain. Our results also highlight the potential of therapeutic/preventive approaches against $\mathrm{AD}$ by targeting astrocytes.

\section{References}

Agrawal SM, Yong VW (2011) The many faces of EMMPRIN: roles in neuroinflammation. Biochim Biophys Acta 1812:213-219.

Allen M, Carrasquillo MM, Funk C, Heavner BD, Zou F, Younkin CS, Burgess JD, Chai HS, Crook J, Eddy JA, Li H, Logsdon B, Peters MA, Dang KK, Wang X, Serie D, Wang C, Nguyen T, Lincoln S, Malphrus K, et al. (2016) Human whole genome genotype and transcriptome data for Alzheimer's and other neurodegenerative diseases. Sci Data 3:160089.
Bazinet RP, Layé S (2014) Polyunsaturated fatty acids and their metabolites in brain function and disease. Nat Rev Neurosci 15:771-785.

Beroun A, Mitra S, Michaluk P, Pijet B, Stefaniuk M, Kaczmarek L (2019) MMPs in learning and memory and neuropsychiatric disorders. Cell Mol Life Sci 76:3207-3228.

Chiu YW, Hori Y, Ebinuma I, Sato H, Hara N, Ikeuchi T, Tomita T (2020) Identification of calcium and integrin-binding protein 1 as a novel regulator of production of amyloid $\beta$ peptide using CRISPR/Cas9-based screening system. FASEB J 34:7661-7674

Citron BA, Dennis JS, Zeitlin RS, Echeverria V (2008) Transcription factor Sp1 dysregulation in Alzheimer's disease. J Neurosci Res 86:2499-2504.

Das M, Das S (2019) Docosahexaenoic acid (DHA) induced morphological differentiation of astrocytes is associated with transcriptional upregulation and endocytosis of $\beta 2$-AR. Mol Neurobiol 56:2685-2702.

Dragano NR, Solon C, Ramalho AF, de Moura RF, Razolli DS, Christiansen E, Azevedo C, Ulven T, Velloso LA (2017) Polyunsaturated fatty acid receptors, GPR40 and GPR120, are expressed in the hypothalamus and control energy homeostasis and inflammation. J Neuroinflammation 14:91.

Florent S, Malaplate-Armand C, Youssef I, Kriem B, Koziel V, Escanyé MC, Fifre A, Sponne I, Leininger-Muller B, Olivier JL, Pillot T, Oster T (2006) Docosahexaenoic acid prevents neuronal apoptosis induced by soluble amyloid- $\beta$ oligomers. J Neurochem 96:385-395.

Fukumoto H, Tomita T, Matsunaga H, Ishibashi Y, Saido TC, Iwatsubo T (1999) Primary cultures of neuronal and non-neuronal rat brain cells secrete similar proportions of amyloid $\beta$ peptides ending at $\mathrm{A} \beta 40$ and A $\beta$ 42. Neuroreport 10:2965-2969.

Gotoh C, Hong YH, Iga T, Hishikawa D, Suzuki Y, Song SH, Choi KC, Adachi T, Hirasawa A, Tsujimoto G, Sasaki S, Roh SG (2007) The regulation of adipogenesis through GPR120. Biochem Biophys Res Commun 354:591-597.

Hamazaki H (1996) Cathepsin D is involved in the clearance of Alzheimer's $\beta$-amyloid protein. FEBS Lett 396:139-142.

Han L, Song S, Niu Y, Meng M, Wang C (2017) Eicosapentaenoic acid (EPA) induced macrophages activation through GPR120-mediated Raf-ERK1/ 2-IKK $\beta$-NF- $\kappa$ B p65 signaling pathways. Nutrients 9:937.

Heras-Sandoval D, Pedraza-Chaverri J, Pérez-Rojas JM (2016) Role of docosahexaenoic acid in the modulation of glial cells in Alzheimer's disease. J Neuroinflammation 13:61.

Hilgendorf KI, Johnson CT, Mezger A, Rice SL, Norris AM, Demeter J, Greenleaf WJ, Reiter JF, Kopinke D, Jackson PK (2019) Omega-3 fatty acids activate ciliary FFAR4 to control adipogenesis. Cell 179:1289-1305. e21.

Hirasawa A, Tsumaya K, Awaji T, Katsuma S, Adachi T, Yamada M, Sugimoto Y, Miyazaki S, Tsujimoto G (2005) Free fatty acids regulate gut incretin glucagon-like peptide-1 secretion through GPR120. Nat Med 11:90-94.

Hori Y, Hashimoto T, Nomoto H, Hyman BT, Iwatsubo T (2015) Role of apolipoprotein $\mathrm{E}$ in $\beta$-amyloidogenesis: isoform-specific effects on protofibril to fibril conversion of a $\beta$ in vitro and brain a $\beta$ deposition in vivo. J Biol Chem 290:15163-15174.

Hu J, Igarashi A, Kamata M, Nakagawa H (2001) Angiotensin-converting enzyme degrades Alzheimer amyloid $\beta$-peptide (A $\beta$ ); retards $\mathrm{A} \beta$ aggregation, deposition, fibril formation; and inhibits cytotoxicity. J Biol Chem 276:47863-47868

Ichimura A, Hirasawa A, Poulain-Godefroy O, Bonnefond A, Hara T, Yengo L, Kimura I, Leloire A, Liu N, Iida K, Choquet H, Besnard P, Lecoeur C, Vivequin S, Ayukawa K, Takeuchi M, Ozawa K, Tauber M, Maffeis C, Morandi A, et al. (2012) Dysfunction of lipid sensor GPR120 leads to obesity in both mouse and human. Nature 483:350-354.

Ishihara T, Yoshida M, Arita M (2019) Omega-3 fatty acid-derived mediators that control inflammation and tissue homeostasis. Int Immunol 31:559567.

Jackson HM, Soto I, Graham LC, Carter GW, Howell GR (2013) Clustering of transcriptional profiles identifies changes to insulin signaling as an early event in a mouse model of Alzheimer's disease. BMC Genomics $14: 831-812$

Jankowsky JL, Fadale DJ, Anderson J, Xu GM, Gonzales V, Jenkins NA, Copeland NG, Lee MK, Younkin LH, Wagner SL, Younkin SG, Borchelt DR (2004) Mutant presenilins specifically elevate the levels of the 42 residue $\beta$-amyloid peptide in vivo: evidence for augmentation of a 42 -specific $\gamma$ secretase. Hum Mol Genet 13:159-170. 
Jonsson T, Atwal JK, Steinberg S, Snaedal J, Jonsson PV, Bjornsson S, Stefansson H, Sulem P, Gudbjartsson D, Maloney J, Hoyte K, Gustafson A, Liu Y, Lu Y, Bhangale T, Graham RR, Huttenlocher J, Bjornsdottir G, Andreassen OA, Jönsson EG, et al. (2012) A mutation in APP protects against Alzheimer's disease and age-related cognitive decline. Nature 488:96-99.

Kidana K, Tatebe T, Ito K, Hara N, Kakita A, Saito T, Takatori S, Ouchi Y, Ikeuchi T, Makino M, Saido TC, Akishita M, Iwatsubo T, Hori Y, Tomita $\mathrm{T}$ (2018) Loss of kallikrein-related peptidase 7 exacerbates amyloid pathology in Alzheimer's disease model mice. EMBO Mol Med 10:e8184.

Kikuchi K, Kidana K, Tatebe T, Tomita T (2017) Dysregulated metabolism of the amyloid- $\beta$ protein and therapeutic approaches in Alzheimer disease. J Cell Biochem 118:4183-4190.

Kim HY, Akbar M, Kim YS (2010) Phosphatidylserine-dependent neuroprotective signaling promoted by docosahexaenoic acid. Prostaglandins Leukot Essent Fatty Acids 82:165-172.

Lewis DL, Hagstrom JE, Loomis AG, Wolff JA, Herweijer H (2002) Efficient delivery of siRNA for inhibition of gene expression in postnatal mice. Nat Genet 32:107-108.

Liao MC, Van Nostrand WE (2010) Degradation of soluble and fibrillar amyloid $\beta$-protein by matrix metalloproteinase (MT1-MMP) in vitro. Biochemistry 49:1127-1136.

Liao MC, Ahmed M, Smith SO, Van Nostrand WE (2009) Degradation of amyloid $\beta$ protein by purified myelin basic protein. J Biol Chem 284:28917-28925.

Liu JJ, Green P, Mann JJ, Rapoport SI, Sublette ME (2015) Pathways of polyunsaturated fatty acid utilization: implications for brain function in neuropsychiatric health and disease. Brain Res 1597:220-246.

Mawuenyega KG, Sigurdson W, Ovod V, Munsell L, Kasten T, Morris JC, Yarasheski KE, Bateman RJ (2010) Decreased clearance of CNS $\beta$-amyloid in Alzheimer's disease. Science 330:1774.

McDermott JR, Gibson AM (1996) Degradation of Alzheimer's beta-amyloid protein by human cathepsin D. Neuroreport 7:2163-2166.

Milligan G, Alvarez-Curto E, Hudson BD, Prihandoko R, Tobin AB (2017) FFA4/GPR120: pharmacology and therapeutic opportunities. Trends Pharmacol Sci 38:809-821.

Minkeviciene R, Ihalainen J, Malm T, Matilainen O, Keksa-Goldsteine V, Goldsteins G, Iivonen H, Leguit N, Glennon J, Koistinaho J, Banerjee P, Tanila H (2008) Age-related decrease in stimulated glutamate release and vesicular glutamate transporters in APP/PS1 transgenic and wild-type mice. J Neurochem 105:584-594.

Miyagawa T, Ebinuma I, Morohashi Y, Hori Y, Young Chang M, Hattori H, Maehara T, Yokoshima S, Fukuyama T, Tsuji S, Iwatsubo T, Prendergast GC, Tomita T (2016) BIN1 regulates BACE1 intracellular trafficking and amyloid- $\beta$ production. Hum Mol Genet 25:ddw146.

Morris MC, Evans DA, Bienias JL, Tangney CC, Bennett DA, Wilson RS, Aggarwal N, Schneider J (2003) Consumption of fish and n-3 fatty acids and risk of incident Alzheimer disease. Arch Neurol 60:940-946.

O’Brien JS, Sampson EL (1965) Lipid composition of the normal human brain: gray matter, white matter, and myelin. J Lipid Res 6:537-544.

Oh DY, Olefsky JM (2016) G protein-coupled receptors as targets for anti-diabetic therapeutics. Nat Rev Drug Discov 15:161-172.

Oh DY, Talukdar S, Bae EJ, Imamura T, Morinaga H, Fan W, Li P, Lu WJ, Watkins SM, Olefsky JM (2010) GPR120 is an omega-3 fatty acid receptor mediating potent anti-inflammatory and insulin-sensitizing effects. Cell 142:687-698.

Oh DY, Walenta E, Akiyama TE, Lagakos WS, Lackey D, Pessentheiner AR, Sasik R, Hah N, Chi TJ, Cox JM, Powels MA, Di Salvo J, Sinz C, Watkins SM, Armando AM, Chung H, Evans RM, Quehenberger O, McNelis J, Bogner-Strauss JG, et al. (2014) A Gpr120-selective agonist improves insulin resistance and chronic inflammation in obese mice. Nat Med 20:942-947

Ohki Y, Higo T, Uemura K, Shimada N, Osawa S, Berezovska O, Yokoshima S, Fukuyama T, Tomita T, Iwatsubo T (2011) Phenylpiperidine-type $\gamma$-secretase modulators target the transmembrane domain 1 of presenilin 1. EMBO J 30:4815-4824.

Okuno H, Akashi K, Ishii Y, Yagishita-Kyo N, Suzuki K, Nonaka M, Kawashima T, Fujii H, Takemoto-Kimura S, Abe M, Natsume R, Chowdhury S, Sakimura K, Worley PF, Bito H (2012) Inverse synaptic tagging of inactive synapses via dynamic interaction of Arc/Arg3.1 with CaMKII $\beta$. Cell 149:886-898.
Podlisny MB, Ostaszewski BL, Squazzo SL, Koo EH, Rydell RE, Teplow DB, Selkoe DJ (1995) Aggregation of secreted amyloid $\beta$-protein into sodium dodecyl sulfate-stable oligomers in cell culture. J Biol Chem 270:95649570.

Qi-Takahara Y, Morishima-Kawashima M, Tanimura Y, Dolios G, Hirotani N, Horikoshi Y, Kametani F, Maeda M, Saido TC, Wang R, Ihara Y (2005) Longer forms of amyloid $\beta$ protein: implications for the mechanism of intramembrane cleavage by $\gamma$-secretase. J Neurosci 25:436-445.

Qiu WQ, Walsh DM, Ye Z, Vekrellis K, Zhang J, Podlisny MB, Rosner MR, Safavi A, Hersh LB, Selkoe DJ (1998) Insulin-degrading enzyme regulates extracellular levels of amyloid $\beta$-protein by degradation. J Biol Chem 273:32730-32738.

Qureshi HY, Sylvester J, El Mabrouk M, Zafarullah M (2005) TGF$\beta$-induced expression of tissue inhibitor of metalloproteinases- 3 gene in chondrocytes is mediated by extracellular signal-regulated kinase pathway and Sp1 transcription factor. J Cell Physiol 203:345-352.

Ren Z, Chen L, Wang Y, Wei X, Zeng S, Zheng Y, Gao C, Liu H (2019) Activation of the omega-3 fatty acid receptor GPR120 protects against focal cerebral ischemic injury by preventing inflammation and apoptosis in mice. J Immunol 202:747-759.

Ries M, Sastre M (2016) Mechanisms of A $\beta$ clearance and degradation by glial cells. Front Aging Neurosci 8:1-9.

Rivera S, García-González L, Khrestchatisky M, Baranger K (2019) Metalloproteinases and their tissue inhibitors in Alzheimer's disease and other neurodegenerative disorders. Cell Mol Life Sci 76:3167-3191.

Roher AE, Kasunic TC, Woods AS, Cotter RJ, Ball MJ, Fridman R (1994) Proteolysis of $\mathrm{A} \beta$ peptide from Alzheimer disease brain by gelatinase $\mathrm{A}$. Biochem Biophys Res Commun 205:1755-1761.

Saido T, Leissring MA (2012) Proteolytic degradation of amyloid $\beta$-protein. Cold Spring Harb Perspect Med 2:a006379. PMC]

Schwab JM, Chiang N, Arita M, Serhan CN (2007) Resolvin E1 and protectin D1 activate inflammation-resolution programmes. Nature 447:869-874.

Shirotani K, Tsubuki S, Iwata N, Takaki Y, Harigaya W, Maruyama K, Kiryu-Seo S, Kiyama H, Iwata H, Tomita T, Iwatsubo T, Saido TC (2001) Neprilysin degrades both amyloid $\beta$ peptides 1-40 and 1-42 most rapidly and efficiently among thiorphan- and phosphoramidon-sensitive endopeptidases. J Biol Chem 276:21895-21901.

Sparks SM, Chen G, Collins JL, Danger D, Dock ST, Jayawickreme C, Jenkinson S, Laudeman C, Leesnitzer MA, Liang X, Maloney P, McCoy DC, Moncol D, Rash V, Rimele T, Vulimiri P, Way JM, Ross S (2014) Identification of diarylsulfonamides as agonists of the free fatty acid receptor 4 (FFA4/GPR120). Bioorg Med Chem Lett 24:3100-3103.

Stewart SA, Dykxhoorn DM, Palliser D, Mizuno H, Yu EY, An DS, Sabatini DM, Chen IS, Hahn WC, Sharp PA, Weinberg RA, Novina CD (2003) Lentivirus-delivered stable gene silencing by RNAi in primary cells. RNA 9:493-501.

Taguchi A, Kawana K, Tomio K, Yamashita A, Isobe Y, Nagasaka K, Koga K, Inoue $\mathrm{T}$, Nishida $\mathrm{H}$, Kojima S, Adachi K, Matsumoto $\mathrm{Y}$, Arimoto $\mathrm{T}$, Wada-Hiraike O, Oda K, Kang JX, Arai H, Arita M, Osuga Y, Fujii T (2014) Matrix metalloproteinase (MMP)-9 in cancer-associated fibroblasts (CAFs) is suppressed by omega-3 polyunsaturated fatty acids in vitro and in vivo. PLoS One 9:e89605

Tomita T (2017) Aberrant proteolytic processing and therapeutic strategies in Alzheimer disease. Adv Biol Regul 64:33-38.

Tomita T, Maruyama K, Saido TC, Kume H, Shinozaki K, Tokuhiro S, Capell A, Walter J, Grünberg J, Haass C, Iwatsubo T, Obata K (1997) The presenilin 2 mutation (N141I) linked to familial Alzheimer disease (Volga German families) increases the secretion of amyloid $\beta$ protein ending at the 42nd (or 43rd) residue. Proc Natl Acad Sci USA 94:20252030.

Van Nostrand WE, Porter M (1999) Plasmin cleavage of the amyloid $\beta$-protein: alteration of secondary structure and stimulation of tissue plasminogen activator activity. Biochemistry 38:11570-11576.

Wang M, Beckmann ND, Roussos P, Wang E, Zhou X, Wang Q, Ming C, Neff R, Ma W, Fullard JF, Hauberg ME, Bendl J, Peters MA, Logsdon B, Wang P, Mahajan M, Mangravite LM, Dammer EB, Duong DM, Lah JJ, et al. (2018) The Mount Sinai cohort of large-scale genomic, transcriptomic and proteomic data in Alzheimer's disease. Sci Data 5:1-16.

Watson SJ, Brown AJ, Holliday ND (2012) Differential signaling by splice variants of the human free fatty acid receptor GPR120. Mol Pharmacol 81:631-642. 
Watterson KR, Hansen SV, Hudson BD, Alvarez-Curto E, Raihan SZ, Azevedo CM, Martin G, Dunlop J, Yarwood SJ, Ulven T, Milligan G (2017) Probe-dependent negative allosteric modulators of the long-chain free fatty acid receptor FFA4. Mol Pharmacol 91:630641

Yamin R, Bagchi S, Hildebrant R, Scaloni A, Widom RL, Abraham CR (2007) Acyl peptide hydrolase, a serine proteinase isolated from conditioned medium of neuroblastoma cells, degrades the amyloid- $\beta$ peptide. J Neurochem 100:458-467.

Yan D, Chen D, Hawse JR, van Wijnen AJ, Im HJ (2013) Bovine lactoferricin induces TIMP-3 via the ERK1/2-Sp1 axis in human articular chondrocytes. Gene 517:12-18.

Yan P, Hu X, Song H, Yin K, Bateman RJ, Cirrito JR, Xiao Q, Hsu FF, Turk JW, Xu J, Hsu CY, Holtzman DM, Lee JM (2006) Matrix metalloproteinase-9 degrades amyloid- $\beta$ fibrils in vitro and compact plaques in situ. J Biol Chem 281:24566-24574.
Yu JZ, Wang J, Sheridan SD, Perlis RH, Rasenick MM (2020) N-3 polyunsaturated fatty acids promote astrocyte differentiation and neurotrophin production independent of cAMP in patient-derived neural stem cells. Mol Psychiatry Advance online publication. Retrieved Jun 5, 2020. doi: 10.1038/s41380-020-0786-5.

Yun EJ, Song KS, Shin S, Kim S, Heo JY, Kweon GR, Wu T, Park JI, Lim K (2016) Docosahexaenoic acid suppresses breast cancer cell metastasis by targeting matrix-metalloproteinases. Oncotarget 7:49961-49971.

Zhang W, Zhang H, Mu H, Zhu W, Jiang X, Hu X, Shi Y, Leak RK, Dong Q, Chen J, Gao Y (2016) Omega-3 polyunsaturated fatty acids mitigate blood-brain barrier disruption after hypoxic-ischemic brain injury. Neurobiol Dis 91:37-46.

Zhao Y, Calon F, Julien C, Winkler JW, Petasis NA, Lukiw WJ, Bazan NG (2011) Docosahexaenoic acid-derived neuroprotectin D1 induces neuronal survival via secretase- and PPAR $\gamma$-mediated mechanisms in Alzheimer's disease models. PLoS One 6:e15816. 